\title{
Evaluation of United Nations-supported pilot projects for the prevention of mother-to-child transmission of HIV: Overview of findings
}

Naomi Rutenberg

Population Council

Carolyn Baek

Sam Kalibala

Population Council

James Rosen

Follow this and additional works at: https://knowledgecommons.popcouncil.org/departments_sbsr-hiv How does access to this work benefit you? Let us know!

\section{Recommended Citation}

Rutenberg, Naomi, Carolyn Baek, Sam Kalibala, and James Rosen. 2003. "Evaluation of United Nationssupported pilot projects for the prevention of mother-to-child transmission of HIV: Overview of findings," HIV/AIDS Working Paper. New York: UNICEF. 
EVALUATION OF

UNITED NATIONS-SUPPORTED

PILOT PROJECTS FOR THE

PREVENTION OF

MOTHER-TO-CHILD

TRANSMISSION OF HIV

OVERVIEW OF FINDINGS

NAOMI RUTENBERG

CAROLYN BAEK

SAM KALIBALA

JAMES ROSEN 
Evaluation of United Nations-supported pilot projects for the prevention of mother-to-child transmission of HIV

(C) United Nations Children's Fund (UNICEF), New York, 2003

UNICEF

3 UN Plaza, NY, NY 10017

August, 2003

This is a working document. It has been prepared to facilitate the exchange of knowledge and to stimulate discussion.

The text has not been edited to official publication standards and UNICEF accepts no responsibility for errors.

The designations in this publication do not imply an opinion on legal status of any country or territory, or of its authorities, or the delimitation of frontiers. 


\section{ABSTRACT}

This overview report presents key findings from an evaluation of UN-supported pilot PMTCT projects in eleven countries, including: Botswana, Burundi, Cote d'Ivoire, Honduras, India, Kenya, Rwanda, Tanzania, Uganda, Zambia, and Zimbabwe. Key findings discuss: feasibility and coverage; factors contributing to programme coverage; programme challenges; scaling-up; the special case of low prevalence countries; and recommendations. Recommendations include:

To increase coverage and improve infant feeding counseling:

- supplement clinic staff with lay counselors;

- introduce rapid HIV tests so women can receive same day counseling, HIV testing, and test results;

- improve the quality of HIV and infant feeding counseling by providing job aids and active supervision;

- offer support to PMTCT providers including material support and peer psychosocial support;

- partner with community groups to offer community education and outreach; and

- expand the vision of PMTCT to encompass an active role for fathers and male partners.

To strengthen postnatal support and follow up of HIV-infected women and their infants to assist them with infant feeding, getting care for themselves and their families, and to evaluate the program:

- establish national infant feeding guidelines;

- establish postnatal follow-up protocols;

- forge partnerships between the PMTCT program and NGO care and support groups;

- Enhance referral links between PMTCT programs and HIV care;

- New measurement tools and systems should be developed.

To scale up PMTCT programs the findings suggest:

- expand to new sites but enlarge the scope of activities within existing sites to reach more women; and

- provide a comprehensive package of HIV prevention and care.

The pilot experience has shown that introducing PMTCT programs into antenatal care in a wide variety of settings is feasible and acceptable to a significant proportion of antenatal care clients who have a demand for HIV information, counseling, and testing. As they go to scale, PMTCT programs have much to learn from the pilot phase, during which they successfully reached hundreds of thousands of clients.

\section{KEYWORDS:}

HIVIAIDS, Mother-to-Child Transmission of HIV [MTCT], Care and Support, Voluntary Counseling and Testing [VCT], Scale-up and Monitoring and Evaluation. 


\section{Acknowledgements}

We would like to acknowledge the contributions of the many people who gathered data, shared experiences, and reviewed drafts of this document. Specifically, we would like to thank Dr. Chipepo Kankasa and Dr. Haritiana Rakotomamonjy in Zambia; Dr. Andre Musemakweri, Dr. Paul Edwards, and Dr. Robert Lim Lim in Rwanda; Dr. Luis Roberto Escoto and Dr. Xioleth Rodriguez in Honduras; Dr. P.L. Joshi and Dr. Anne Vincent in India; the MTCT managers and UNICEF focal points in the pilot countries who responded to questionnaires and request for interviews; Dr. Doreen Mulenga and the PMTCT team at UNICEF Headquarters; the regional UNICEF focal points; and the Inter Agency Task Team on PMTCT. We are also grateful to Dr. Doreen Mulenga, Dr. Helene Moller, Dr. Mary Mahy and IATT members from UNFPA and WHO that provided helpful comments on an earlier draft. We would also like to acknowledge the assistance of Malea Hoepf from the Population Council.

Financial support for this evaluation was provided by the UNAIDS Secretariat on behalf of the IATT through a Memorandum of Understanding between UNICEF with the Population Council (MOU/PD/HLTH/01-005) and the Population Council's Horizons Program.

The Population Council's Horizons Program is implemented by the Population Council in collaboration with the International Center for Research on Women, International HIV/AIDS Alliance, Program for Appropriate Technology in Health, Tulane University, Family Health International, and Johns Hopkins University. Horizons is funded by the U.S. Agency for International Development, under the terms of HRN-A-00-97-00012-00. The opinions expressed herein are those of the authors and do not necessarily reflect the views of the U.S. Agency for International Development.

The Population Council is an international, nonprofit, nongovernmental institution that seeks to improve the wellbeing and reproductive health of current and future generations around the world and to help achieve a humane, equitable, and sustainable balance between people and resources. The Council conducts biomedical, social science, and public health research and helps build research capacities in developing countries. Established in 1952, the Council is governed by an international board of trustees. Its New York headquarters supports a global network of regional and country offices.Horizons is funded by the Global Bureau of Health/HIV-AIDS, U.S. Agency for International Development, under the terms of Award No. HRN-A-00-97-00012-00.

The views expressed in this document by the named contributors are solely the responsibility of those contributors. 


\section{Table of Contents}

Abstract 1

$\begin{array}{ll}\text { Acknowledgements } & 2\end{array}$

Acronyms and Abbreviation $\quad 4$

Overview $\quad 5$

A. Introduction 10

B. Evaluation Objectives and Methodology 12

C. Main Findings $\quad 13$

1. Feasibility and Coverage $\quad 13$

2. Factors Contributing to Program Achievements 23

3. Program Challenges $\quad 27$

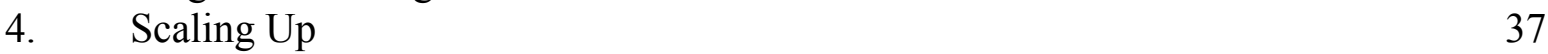

5. The Special Case of Low-Prevalence Countries $\quad 41$

D. Conclusion $\quad 42$

E. Recommendations $\quad 43$

Figures and Tables

Figure 1. $\quad$ PMTCT Program Components and Relationship to Program Prongs 10

Figure 2. $\quad$ Map of Eleven UN-Supported Pilot PMTCT Programs Initiated 1999-2000 13

Figure 3. $\quad$ PMTCT Services at Pilot Sites, January 2000 through June 200215

Figure 4. Percent of ANC Clients Who Receive Pretest Counseling at PMTCT Pilot Sites, January 2000 through June 2002

Figure 5. Percent of ANC Clients Who Had an HIV Test after Pretest Counseling, PMTCT Pilot Sites, January 2000 through June 2002

Figure 6. $\quad$ Percent of HIV-Positive Pregnant Women with an HIV Test Who Received ProphylacticAntiretroviral Drugs, PMTCT Pilot Sites, January 2000 through June 2002

Figure 7. Percent of HIV-Positive Pregnant Women Who Attend ANC Who Received Prophylactic Antiretroviral Drugs, PMTCT Pilot Sites, January 2000 through June 2002

Figure 8. $\quad$ Impact of PMTCT Male Involvement Strategies on Partner Communication in Kenya

Table 1. PMTCT Program Statistics, Kicukiro Health Center, Rwanda, April 1999 June 2002

Table 2. $\quad$ Infant Feeding Practice Following the Introduction of PMTCT Programs in Botswana, Kenya, and Zambia, 2001-2002

Boxes

Box 1: $\quad$ Feasibility studies of short term AZT and NVP interventions to prevent MTCT of HIV in India $\quad 20$

Box 2: $\quad$ What Zambian Clients Say About the PMTCT Program 25

Box 3: $\quad$ Infant feeding counseling and support in Zambia $\quad 31$

Box 4: $\quad$ Botswana's experience with scaling up 38

Box 5: $\quad$ Key scaling up lessons 41

\section{Appendices}

Appendix A. List of Country Progress Reports Reviewed 46

Appendix B. List of Key Informants 


\section{Acronyms and Abbreviations}

$\begin{array}{ll}\text { AIDS } & \text { Acquired Immunodeficiency Syndrome } \\ \text { ANC } & \text { Antenatal care } \\ \text { ARV } & \text { Antiretroviral } \\ \text { AZT } & \text { Zidovudine } \\ \text { ELISA } & \text { Enzyme Linked Immunosorbent Assay } \\ \text { FHI } & \text { Family Health International } \\ \text { HIV } & \text { Human Immunodeficiency Virus } \\ \text { IATT } & \text { Inter Agency Task Team on PMTCT } \\ \text { IMCI } & \text { Integrated Management of Childhood Illness } \\ \text { KAP } & \text { Knowledge, Attitude, Practice } \\ \text { MCH } & \text { Maternal-child health } \\ \text { MTCT } & \text { Mother-to-child transmission of HIV } \\ \text { NARESA } & \text { Network of AIDS Researchers in East and Southern Africa } \\ \text { NGO } & \text { Nongovernmental organization } \\ \text { NVP } & \text { Nevirapine } \\ \text { PCR } & \text { Polymerase chain reaction } \\ \text { PLHA } & \text { Person (or people) living with HIV/AIDS } \\ \text { PMTCT } & \text { Prevention of mother-to-child transmission of HIV } \\ \text { TAC } & \text { Technical Advisory Committe } \\ \text { TRAC } & \text { Treatment and AIDS Research Center, Rwanda } \\ \text { UN } & \text { United Nations } \\ \text { UNAIDS } & \text { United Nations Programme on HIV/AIDS } \\ \text { UNF } & \text { United Nations Fund } \\ \text { UNFIP } & \text { United Nations Fund for International Partnerships } \\ \text { UNFPA } & \text { United Nations Population Fund } \\ \text { UNICEF } & \text { United Nations Children's Fund } \\ \text { USAID } & \text { U.S. Agency for International Development } \\ \text { VCT } & \text { Voluntary counseling and testing for HIV } \\ \text { WHO } & \text { World Health Organization } \\ & \end{array}$




\section{Overview}

Worldwide about 800,000 children a year get HIV infection from their mothers-either during pregnancy, childbirth, or breastfeeding. Countries have the potential to prevent a large share of these infections through low-cost, effective interventions. UN agencies have taken the lead in helping developing countries to mount programs for prevention of mother-to-child transmission (PMTCT). This overview report presents key findings from an evaluation of UN-supported pilot PMTCT projects in eleven countries, including: Botswana, Burundi, Cote d'Ivoire, Honduras, India, Kenya, Rwanda, Tanzania, Uganda, Zambia, and Zimbabwe. Key findings include:

\section{Feasibility and Coverage}

PMTCT programs are feasible in low-resource settings, but still face many challenges. In virtually every pilot country, maternal-child health settings are able to effectively integrate PMTCT programs. Currently, 205 sites in a wide range of settings offer PMTCT services in ten of the original eleven pilot countries; Botswana has scaled up its program to the national level. Between January 2000 and the end of June 2002, pilot sites had counseled 385,000 women, given HIV tests to 280,000, and prescribed antiretroviral (ARV) prophylaxis to almost 12,000 women. Yet, PMTCT programs still do not help as many women as they could. On average, thirty percent of women who visit the PMTCT sites for antenatal care (ANC) are not counseled on PMTCT. Of those women who do receive counseling, three out of ten are not tested for HIV. Of those women who test positive for HIV, just under half receive antiretroviral drugs. Although these proportions have increased over time, raising them further remains a critical task for program managers and PMTCT advocates.

The coverage of PMTCT counseling is increasing but staff shortages and service delivery organization continue to affect uptake. Broad averages mask significant differences in the coverage of PMTCT counseling across countries. The percent of women who come to clinics for antenatal care receiving individual HIV pretest counseling ranges from less than 25 percent in Zambia to well over 90 percent in Burundi and Rwanda. An important trend is the tendency for pilot sites to increase the proportion of women they are able to offer pretest counseling over time. This is the case in countries such as India, Kenya and Uganda, where, by the end of the evaluation period, antenatal clinics were counseling over 90 percent of clients. Uptake of HIV counseling services is negatively affected by staff shortages and the organization of service delivery, which influence both the supply and demand for HIV counseling.

Including HIV tests as part of routine antenatal care increases the proportion of women who are tested but significant minorities do not collect test results. The percentage of women who accept an HIV test after counseling ranges between 64 and 83 percent. Although counseling quality is one key factor motivating women to take the HIV test, making the test a routine part of antenatal care is also important to encouraging women to be tested. Programs do not routinely report the proportion of women who collect their test results but special studies in Kenya and Zambia suggest that about onequarter of women do not get their results. Possible reasons for this include results not being ready; women change their minds or were never sure about the benefit of taking the test, and partner opposition. 
ARV provision is working well, but coverage remains a challenge. Provision of ARV in the maternalchild health $(\mathrm{MCH})$ setting has been relatively simple and problem free but the drugs are still not reaching many pregnant women. In nine of eleven pilot countries only between 40 and 60 percent of women who test positive for HIV at the PMTCT site get ARVs. Moreover, in most countries, onequarter or fewer of all HIV-positive pregnant women receiving antenatal services ultimately get a short course of ARVs. Although still too low, this proportion has shown an encouraging increase over time.

HIV-positive women at the pilot sites did not receive a complete course of ARVs for a variety of reasons, including: having not yet reached thirty-four or thirty-six weeks gestation when zidovudine is initiated and not coming back after; not taking the full dosage of their ARV; partner opposition; concern about taking drugs in pregnancy; they deliver at home or another facility and thus miss out on the intrapartum doses; or they reach the health facility when in active labor and thus too late for intrapartum doses. To increase use of ARVs, programs are switching to or relying more heavily on Nevirapine, including giving women Nevirapine to take home with them and ingest at the onset of labor.

The benefits of PMTCT go beyond the ARVS provided. PMTCT programs have greatly increased the amount of health education on HIV/AIDS and PMTCT and specifically information on how to prevent transmission provided to women, and program evaluations show knowledge is increasing. PMTCT services are providing information to clients, which is tailored to their concerns and context about their own risk, the health of their partner and children, and their relationship with their partner. Women are empowered when they learn they are not helpless to respond to HIV.

A PMTCT Health Information System is a critical management tool. Creating and maintaining a health information system that collects information on the number of women utilizing various PMTCT services is vitally important to monitor and evaluate the volume of services provided, program coverage, how successful the program is at reaching women in need and where bottlenecks or breakdowns within services occur. This information is a critical management tool for planning, budgeting, monitoring and evaluating PMTCT programs.

\section{Factors Contributing to Program Achievements}

Motivated health workers are the backbone of PMTCT. PMTCT pilot programs have now trained nearly 3,300 health workers, on topics that include the minimum package for PMTCT, general counseling skills, infant feeding counseling, and laboratory tests. The introduction of PMTCT services has provided extra motivation and empowered health providers by — for the first time for manygiving them tools to help clients and their babies fight HIV. Nonetheless, a shortage of staff in general, and trained staff in particular, is still among the most important constraints on the program.

Levels of quality of care in PMTCT programs are encouraging. PMTCT services are tailoring information to respond to client concerns about their own risk, the health of their partner and children, and their relationship with their partner. The response of clients and community members to PMTCT services has been widely positive. 
PMTCT programs contribute to stigma reduction. While most PMTCT programs report experiences with stigma in health care settings and in communities, generally clients and program managers do not highlight stigma and discrimination as a major program challenge. Similarly, the evaluation found no evidence from program staff that the introduction of PMTCT programs in the MCH setting has discouraged use of traditional antenatal care. To the contrary, PMTCT programs have helped women safely disclose their HIV testing experience and status to their partners family and contributed to stigma reduction in the community by fostering discussions and normalizing HIV counseling, testing, and care.

\section{Program Challenges}

Communication activities to mobilize communities lag behind clinical services. An integrated PMTCT communication strategy provides a strong base to address key PMTCT-related issues. However, the additional management and resource burden of developing and implementing a communication strategy has delayed or limited the implementation of such strategies in many sites. Programs have generally concentrated first on communications at the clinics to provide materials for providers, clients, and their families. Partly this is because activities in the community are more challenging to sustain.

Attention to engaging male partners is insufficient. In most settings, male involvement and support is critical to improving women's uptake of core PMTCT services as well as for primary prevention of HIV and avoiding unintended pregnancy. Nonetheless, pilot programs have done relatively little to involve men and many program managers see encouraging male involvement as one of their challenges.

Infant feeding remains the most challenging component of PMTCT programs. Global guidance for HIV and infant feeding counseling exists, but each country needs to develop or adapt policy guidelines based on local conditions. Programs use a variety of models for infant feeding counseling. Most use nurse-midwives, some use specialized counselors, and one program, in Rwanda, has separate nutrition centers. Each approach has its advantages and disadvantages. Despite training, staff knowledge and counseling abilities remain weak. Counselors frequently steer a woman towards an infant feeding method based solely on her HIV status rather than a comprehensive assessment of her social and economic resources for implementing various feeding options. Moreover, very few programs provide ongoing support for women to carry out their infant feeding choice once their baby is born.

Programs recognize the importance of care and support but need more comprehensive services. PMTCT pilot programs vary widely in the development of care and support services, with Botswana leading with the most advanced care and support network. Efforts in other countries, however, are patchy at best. PMTCT programs do little in the way of proactive follow-up care for infants.

PMTCT programs need to strengthen related antenatal, family planning, and primary prevention services. While PMTCT programs have generally succeeded in introducing core services such as voluntary counseling and testing (VCT) and ARV provision into the $\mathrm{MCH}$ care setting, they have not made much headway in addressing related needs, including primary prevention of HIV in women, prevention of unintended pregnancy in HIV-infected women, and improved antenatal and obstetric 
care. Attention to prevention and treatment of sexually transmitted infections, maternal nutrition, and basic supplies for antenatal care remain inadequate.

\section{Scaling Up}

Government support and high-level coordination is key as programs move from piloting to scaling up. The complex and multisectoral nature of PMTCT programs demands strong leadership and good coordination to ensure the success of both pilot and scaled-up programs. A number of countries have taken steps in the right direction through organizational changes, establishment of national coordinating bodies, and assignment of full-time staff to manage national programs.

Human resources will be critical in expanding coverage and scaling up. Scaling up will require resolving a number of human resource problems, including staff shortages, the need for large-scale training and ongoing worker support, and inadequate remuneration.

Existing ANC/MCH supply systems should be strengthened to effectively integrate and scale up PMTCT services. Scaling up access to PMTCT services requires using the existing ANC/MCH procurement and supply systems for PMTCT supplies. Strengthening this supply chain should be a priority activity or PMTCT services will be vulnerable to the same supply problems that beleaguer many MCH programs.

\section{The Special Case of Low-Prevalence Countries}

Programs in low-prevalence settings report similar experiences as high prevalence settings but also face unique opportunities and challenges. Two of the pilots took place in relatively low prevalence settings in Honduras and India to learn how the introduction and scaling up of programs might differ in such a setting. The experiences in the lower prevalence sites have much in common with the higher prevalence sites in Africa though also significant differences. One unique factor contributing to success in India was the addition of qualified counselors which ensured a high quality of counseling services overall. India also differs from most sites in that resident doctors and nurses who rotate between departments with relative frequency and may not be up to date with the PMTCT intervention provide a significant proportion of PMTCT services. An operational difficulty identified in the AZT and NVP feasibility studies in India has been coverage for HIV positive women who choose to deliver at home, as is the case when they move away to their parental homes for the delivery.

Due to its low prevalence and small size of its target population, the PMTCT program in Honduras has a number of characteristics making it different from both those in high-prevalence African countries and India. Because almost all clients are HIV-negative, VCT is less emotionally burdensome for both clients and providers and the small number of women testing HIV-positive means that the program can spend more resources to provide individualized follow-up support. On the other hand additional advocacy for PMTCT is required, because HIV/AIDS is a lower priority health issue for governments in low-prevalence countries, and international donors have little interest in supporting programs compared to some high-prevalence settings. 


\section{Recommendations}

To increase coverage and improve infant feeding counseling: Experience at the pilot sites as well as from PMTCT programs elsewhere suggests several actions which may help keep women in the program to receive the full benefit of HIV and infant feeding counseling, HIV testing, and ARV prophylaxis:

- $\quad$ supplementing clinic staff with lay counselors;

- introducing rapid HIV tests so women can receive same day counseling, HIV testing, and test results;

- improving the quality of HIV and infant feeding counseling by providing job aids and active supervision;

- offering support to PMTCT providers including material support and peer psychosocial support;

- partnering with community groups to offer community education and outreach; and

- expanding the vision of PMTCT to encompass an active role for fathers and male partners.

\section{To strengthen postnatal support and follow up of HIV-infected women and their infants to assist} them with infant feeding, getting care for themselves and their families, and to evaluate the program: PMTCT programs should establish national infant feeding guidelines which include recommendations for HIV-infected women, based on an assessment of local feasibility, acceptability, affordability, safety and sustainability of various feeding options. Also needed are postnatal follow-up protocols including outreach and support groups to help mothers safely apply their infant feeding decision, encourage good maternal nutrition, and address infant feeding after six months. Pilot sites have forged many successful partnerships between the PMTCT program and NGO care and support groups, and scaled-up programs should replicate similar partnerships at all sites. New opportunities for addressing postnatal care for HIV-infected women and enhanced referral links between PMTCT programs and HIV care are currently being devised as part of the development of MTCT-Plus programs. New measurement tools and systems should be developed through field trials, and expanded programs will require monitoring and evaluation staff.

To scale up: PMTCT programs must not only expand to new sites but enlarge the scope of activities within existing sites to reach more women and to provide a comprehensive package of HIV prevention and care. This requires human resources and expertise, coordination and collaboration between partners, a well functioning supply system and resource mobilization. Strong leadership and good coordination of the many institutions and individuals involved is critical to successful scaling up.

The pilot experience has shown that introducing PMTCT programs into antenatal care in a wide variety of settings is feasible and acceptable to a significant proportion of antenatal care clients who have a demand for HIV information, counseling, and testing. In many aspects, however, programs can be strengthened. As they go to scale, PMTCT programs have much to learn from the pilot phase, during which they successfully reached hundreds of thousands of clients. Hopefully, they can translate this knowledge into better services for many more women, children, and families. 


\section{A. Introduction}

The effects of the HIV pandemic among young children are serious and far-reaching. UNAIDS estimates that 800,000 children were infected in 2002 almost all through transmission of the virus from their mothers during pregnancy, childbirth, or breastfeeding. Of these, seven of each eight live in sub-Saharan Africa, and most of the rest live in South and Southeast Asia. AIDS has reversed years of steady progress in child survival, and has already doubled infant death rates in the worst affected countries.

Effective interventions have dramatically reduced the number of children born with HIV in wealthy and middle-income countries. In the poorest countries, however, matching this success will require overcoming significant financial and operational challenges. To help address these challenges, in 1999 the UN embarked on a program of technical and financial support. In 1999, the UNAIDS Secretariat, UNFPA, UNICEF, and WHO launched the Inter Agency Task Team (IATT) on Prevention of MTCT. The IATT aims to give strong, coordinated leadership and guidance to countries for prevention of MTCT (PMTCT). In the view of the IATT, PMTCT is part of broader strategies to prevent the transmission of HIV and sexually transmitted diseases, to care for HIV-positive women and their families, and to promote maternal-child health $(\mathrm{MCH})$.

The IATT has proposed the following four-pronged approach for the prevention of HIV transmission to pregnant women, mothers, and their children:

1. Primary prevention of HIV infection in women

2. Prevention of unintended pregnancy among HIV-infected women

3. Interventions to reduce transmission from HIV-infected pregnant and lactating women to their children

4. Care and support of women, children, and families infected and affected by HIV/AIDS

Recommended PMTCT program components to address each of the four prongs are shown in Figure 1 .

Figure 1: PMTCT Program Components and Relationship to Program Prongs

\begin{tabular}{|c|c|c|c|c|}
\hline \multirow[b]{2}{*}{$\begin{array}{l}\text { Program } \\
\text { Components }\end{array}$} & \multicolumn{4}{|c|}{ Program Prongs } \\
\hline & $\begin{array}{l}\text { Primary } \\
\text { prevention of } \\
\text { HIV infection } \\
\text { in women }\end{array}$ & $\begin{array}{l}\text { Prevention of } \\
\text { unintended } \\
\text { pregnancy } \\
\text { among HIV- } \\
\text { infected women. }\end{array}$ & $\begin{array}{l}\text { Interventions to } \\
\text { reduce transmission } \\
\text { from HIV-infected } \\
\text { pregnant and } \\
\text { lactating women to } \\
\text { their children }\end{array}$ & $\begin{array}{l}\text { Care and support } \\
\text { of women, } \\
\text { children, and } \\
\text { families infected } \\
\text { and affected by } \\
\text { HIV/AIDS }\end{array}$ \\
\hline $\begin{array}{l}\text { Components } \\
\text { introduced into the } \\
\text { PMTCT program }\end{array}$ & & & $\begin{array}{l}\text { HIV counseling and } \\
\text { testing } \\
\text { Short course } \\
\text { antiretrovirals } \\
\text { HIV and infant } \\
\text { feeding counseling and }\end{array}$ & \\
\hline
\end{tabular}




\begin{tabular}{|l|l|l|l|l|}
\hline & & & $\begin{array}{l}\text { support } \\
\text { Male involvement }\end{array}$ & \\
\hline $\begin{array}{l}\text { Components } \\
\text { strengthened by } \\
\text { the PMTCT } \\
\text { program }\end{array}$ & $\begin{array}{l}\text { HIV } \\
\text { prevention }\end{array}$ & Family planning & Antenatal care & Care and support \\
\hline
\end{tabular}

UNICEF appointed PMTCT focal points in 11 countries to specifically address PMTCT and secured 3 million dollars of funding from the United Nations Fund (UNF)/United Nations Fund for International Partnerships (UNFIP) to catalyze the initiation of PMTCT interventions. In addition to the IATT, coordination mechanisms were set up at regional and national levels and mainly UNICEF, at the national level, provided technical support for all aspects of PMTCT. More recently, the IATT has supported regional strategic planning processes.

The UN family took the lead in developing specific tools for PMTCT programs such as assessment tools, training materials, monitoring and evaluation plans and tools and hosted regional meetings of program managers and technical resources which have been milestones in shaping PMTCT program guidelines. WHO has provided technical leadership in the areas of HIV and infant feeding, review of scientific evidence on the different components of a PMTCT program (e.g., efficacy and safety of various regimens for short course of anti-retroviral therapy), development of indicators for monitoring and evaluation, drafting and testing of service delivery guidelines, training materials, and are currently in the process of finalising a care and support reference guide. Glaxo Welcome (now Glaxo Smith Kline) made 30,000 treatment packs of 60 tablets zidovudine $300 \mathrm{mg}$ available to initiate the first pilot programs, as a donation in kind.

UNICEF supported PMTCT pilot projects in eleven low-income countries of Africa, Asia, and Latin America (see Figure 2). The pilot sites operate in a variety of settings: prestigious teaching hospitals, crowded urban health centers, district hospitals with few resources, rural health posts, and in areas of both low and high HIV prevalence. In addition, the secretariats that manage the pilots vary greatly in their composition, structure, and relationship with other HIV and MCH programs. The pilots aim to test the feasibility and sustainability of carrying out PMTCT programs in settings typical of poor, resource-constrained countries, to measure program impact, and to guide expansion of successful programs and initiation of PMTCT programs in other countries.

This overview report summarizes key findings from an evaluation of the pilot projects in all eleven countries. Selected country reports prepared as part of this evaluation ${ }^{1}$ and country reports produced by the PMTCT programs themselves provide greater detail on the experience in specific countries (see Appendix A for a list of country reports).

\footnotetext{
${ }^{1}$ See: Report on the Qualitative Rapid Assessment of the UN-Supported PMTCT Pilot Program in Honduras, August 2630, 2002; PMTCT Evaluation: Report on Discussions with National AIDS Control Organization and Visits to Two Pilot Program Sites in India, 2002; Report on the Rapid Assessment of the UN-Supported PMTCT Pilot Program in Zambia, 2002; and Report on the Rapid Assessment of the UN-Supported PMTCT Initiative in Rwanda, 2002. These reports are available from UNICEF.
} 


\section{B. Evaluation Objectives and Methodology}

\section{B.1. Objectives}

The IATT asked the Population Council to take the lead in evaluating the pilot experience. The evaluation had three main objectives:

- to examine and document progress, experiences, and lessons learned at UN-supported pilot program sites;

- to examine the mechanisms of collaboration, coordination, and linkage with bilateral and nongovernmental organization (NGO) partners; and

- to prepare a practical programming framework for scaling up of PMTCT programs.

This evaluation report focuses primarily on the quantity and quality of services, factors contributing to program achievements and current program challenges. It was not possible within the scope of this evaluation to collect in-depth information or conduct a systematic examination of program support structures such as capacity building, supplies, and monitoring and evaluation. Recommendations for program actions to develop these systems, based primarily on the advice of international and national program mangers, are included in the companion document, "Program Recommendations for Prevention of Mother-to-Child Transmission of HIV: A practical guide for managers."

\section{B.2. Methods}

The Population Council carried out the evaluation between March and December 2002, in close consultation with UNICEF and other IATT members. The evaluation employed a mix of qualitative and quantitative methodologies, including:

- a review of progress reports from the country pilots, that included information on program inputs, activities, achievements, challenges, and (for some countries) costs (see Appendix A for a list of progress reports reviewed);

- interviews (generally by telephone but also face-to-face at the International AIDS Conference 2002 in Barcelona) with key informants such as PMTCT program managers, and technical experts in charge of coordinating PMTCT activities at UNICEF and other donor agencies such as USAID (see Appendix B for list of key informants);

- rapid assessments in two countries (Rwanda and Zambia), and site visits and face-to-face interviews with program managers in two other countries (Honduras and India) that gathered information from site managers, providers, clients, and community members on PMTCT program inputs, the types of PMTCT services offered and received, the quality of those services, and provider, client, and community reactions to the PMTCT program; and

- a collaborative analysis meeting held in September 2002 with members of the IATT. ${ }^{2}$

\footnotetext{
${ }^{2}$ For a report of the collaborative analysis meeting, see: Population Council and UNICEF. 2002. "PMTCT Evaluation Collaborative Analysis Meeting, Washington DC, September 9-10, 2002.” Meeting Report. New York: UNICEF.
} 
Because of time and resource constraints, and variation in existing information by site, the amount and depth of information collected from the pilot sites is somewhat uneven. Despite this limitation, the range and variety of sites included in the pilot phase presents a unique learning opportunity.

\section{Figure 2: Map of Eleven UN-Supported Pilot PMTCT Programs Initiated 1999-2000}

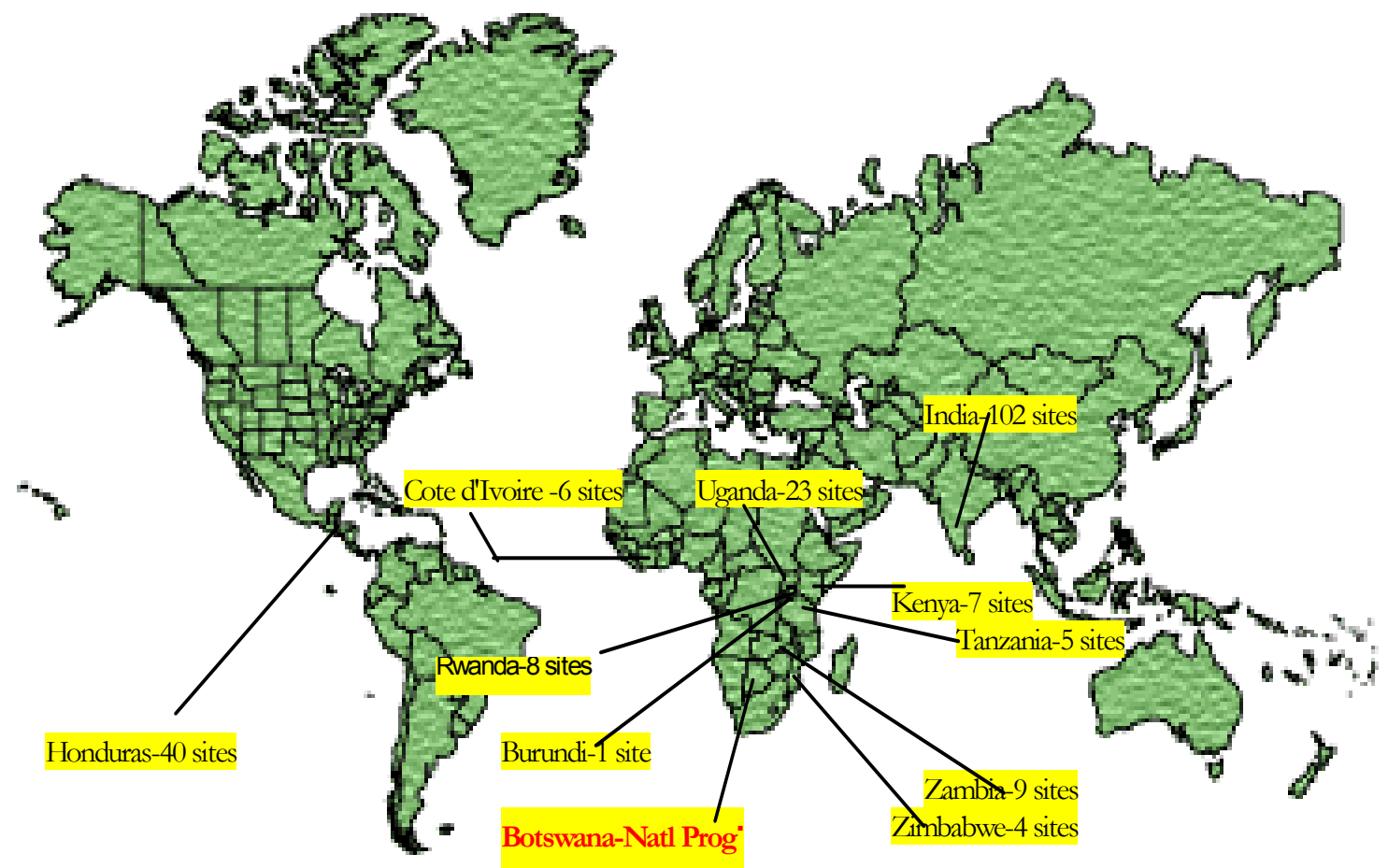

Source: UNICEF. PMTCT Programme News. November 2002. Issue no. 4. HIV/AIDS Unit.

\section{Main Findings}

This section summarizes the evaluation results, grouping main findings into five categories. The first, feasibility and coverage, looks at how well PMTCT programs are being integrated into MCH settings, and reports on the numbers of women served and types of services provided. The second category, factors contributing to program achievements, highlights areas where pilot programs have performed especially well. The third category, program challenges, discusses areas where relatively little progress has been made. The fourth looks at issues related to scaling up. The fifth and final category briefly discusses the special characteristics of PMTCT programs in low-prevalence settings.

\section{C.1. Feasibility and Coverage}

This section examines the integration of PMTCT in the MCH setting, describes the management and implementation structure of the pilot projects, and reports on program coverage and some of the reasons why programs are not reaching as many women as they should. 


\section{Finding: $\quad$ PMTCT programs are feasible in low-resource settings, but still face many challenges.}

Integration. In virtually every pilot country, maternal-child health settings are able to effectively integrate PMTCT programs into existing antenatal and HIV/AIDS programs. PMTCT services are offered as part of routine ANC services and in coordination with the HIV/AIDS programs, particularly voluntary HIV counseling and testing services and HIV/AIDS information, education, and communication programs. Currently, 205 sites offer PMTCT services in ten of the original eleven pilot countries, and Botswana has scaled up its program to the national level (Figure 2). Notably, the effective integration of PMTCT programs has occurred in a wide range of settings: geographically, in three different continents; in both large hospitals and small health centers; in cities and in rural areas; and in areas of high and low HIV prevalence. The pilot PMTCT programs are not vertical programs. Rather, every site has integrated PMTCT into existing MCH services and, for the most part, has carried out the PMTCT program without hiring extra staff. Officials in Kenya cite their ability to provide PMTCT without additional health workers as one of their greatest successes.

Management and Coordination Mechanisms. Primarily, governments have carried out the pilot PMTCT programs, with some NGO support. The principal partners have been ministries of health, national AIDS control programs, and district health teams who are responsible for service provision. Researchers have had substantial involvement in the pilot programs in India, where some pilot sites are based in the medical colleges, and in Kenya where the Network of AIDS Researchers in East and Southern Africa (NARESA) supported the introduction of the program and is carrying out extensive evaluation. Central working groups or similar structures have been established in all the countries that initiated pilot projects to coordinate PMTCT activities and provide technical support (for example, to develop guidelines and training curriculum for a minimum package of care; to review proposed perinatal studies; for evaluation; for dissemination of program experience; and for laboratory support). Generally, the working groups are comprised of government and donor officials and technical experts. The groups also often include managers of NGO programs and representatives of organizations of people living with HIV/AIDS. All programs have some kind of national PMTCT program manager or coordinator, usually a part time position, and a small secretariat that oversees the development of the national PMTCT package and training curriculum, manages training workshops, conducts supervisory visits, monitors PMTCT-related drug distribution and storage, and supervises the collection of program monitoring data.

Program Coverage. Between January 2000 and the end of June 2002, pilot sites had counseled more than 385,000 women, given HIV tests to 270,000 clients and prescribed antiretroviral (ARV) prophylaxis to almost 12,000 women (see Figure 3 ). ${ }^{3}$ Despite these impressive figures, PMTCT programs still do not help as many women as they could. Thirty percent of women who visit the PMTCT sites for antenatal care get no counseling on PMTCT. Of those women who do receive counseling, three out of ten are not tested for HIV. Of those women who test positive for HIV, just under half receive antiretroviral drugs. Raising these proportions remains a critical task for program managers and PMTCT advocates.

\footnotetext{
${ }^{3}$ The statistics on number of services provided for each country is available in the PMTCT Progamme News, published by UNICEF.
} 


\section{Figure 3: PMTCT Services at 11 Pilot Sites \\ January 2000 through June 2002}

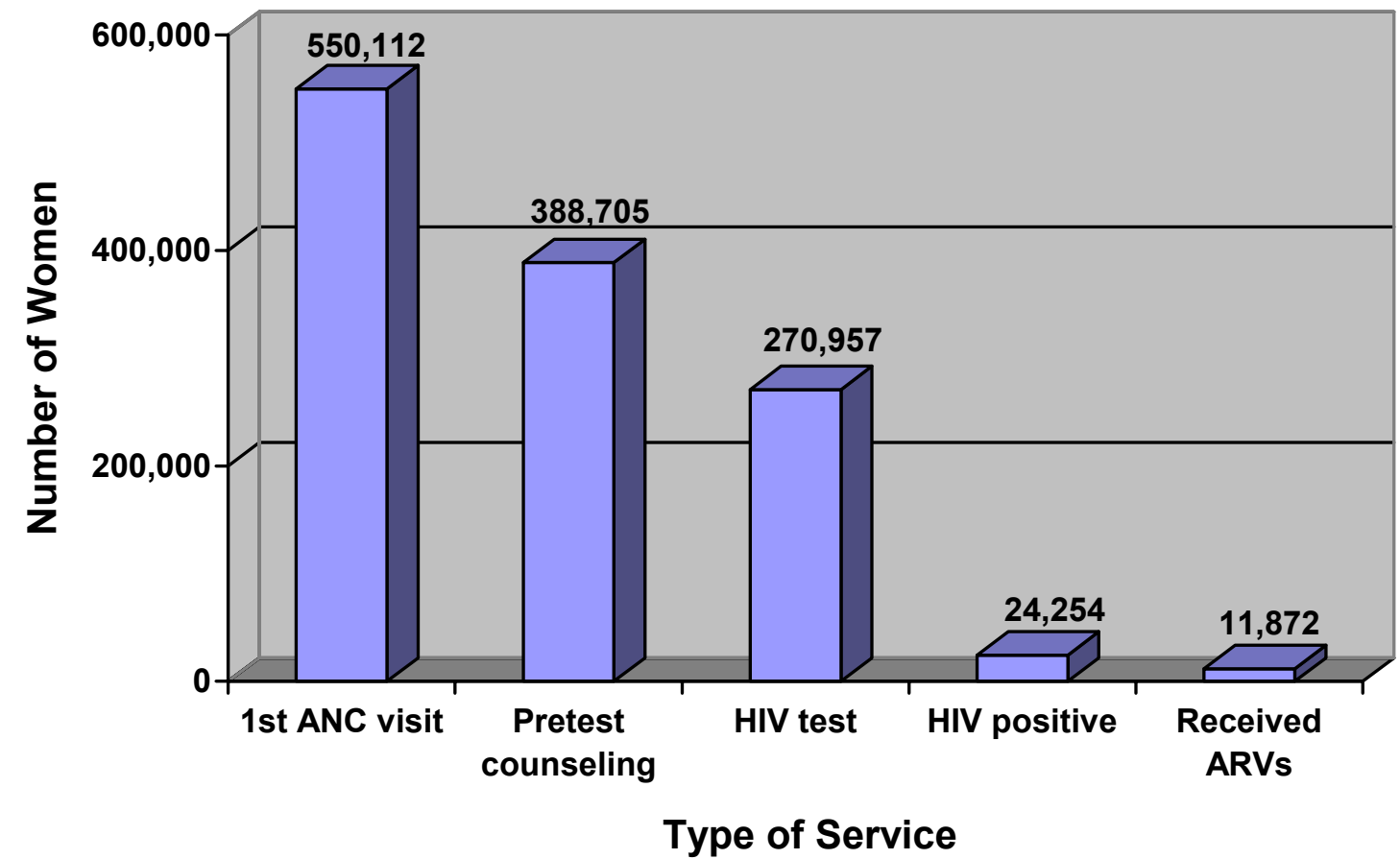

Source: UNICEF. PMTCT Programme News. November2002. Issue no. 4. HIV/AIDS Unit.

Finding: The coverage of PMTCT counseling is increasing but staff shortages and service delivery organization continue to affect uptake.

These broad averages mask significant differences in the coverage of HIV counseling across countries. For example, the percent of women who come to clinics for antenatal care receiving individual HIV pretest counseling ranges from less than 25 percent in Zambia to well over 90 percent in Burundi and Rwanda (see Figure 4). Sites in Burundi and Rwanda, as well as in India, Kenya, and Uganda, offer pretest counseling as a routine component of antenatal care and thus nearly all women who come for services are counseled. The low average figure for Zambia reflects the inclusion of the University Teaching Hospital as one of the pilot sites. This site is a very high-volume referral site, which has struggled to integrate PMTCT as a standard part of care. The proportion of clients receiving counseling at other pilot sites in Zambia averages 40 percent.

Another important trend is the tendency for pilot sites to increase the proportion of women they are able to offer pretest counseling over time. This is the case in countries such as India, Kenya, and Uganda, where, by the end of the evaluation period, antenatal clinics were counseling over 90 percent of clients. 
Uptake of HIV counseling services is negatively affected by staff shortages and the organization of service delivery, which influences both the supply and demand for HIV counseling. Probably the single most important hurdle to providing pretest counseling is a shortage of staff. Good counseling takes time, which is in short supply at many busy clinics where workers already provide antenatal, well-child, and family planning services. At some sites lack of privacy, long waits, or rules that require clients to return another day for counseling further discourage women from being counseled. As demonstrated by the sites that have made pretest counseling routine, adaptations to the staffing and organization of service delivery can achieve quite high coverage. Successful strategies have included hiring additional medical staff, bringing on board nonmedical or lay counselors (either professional or non-professional), re-assigning some $\mathrm{MCH}$ staff to be dedicated counselors, and reorganizing the work hours of staff. 


\section{Figure 4: Percent of ANC Clients Who Receive Pretest Counseling at PMTCT Pilot Sites, January 2000 through June 2002}

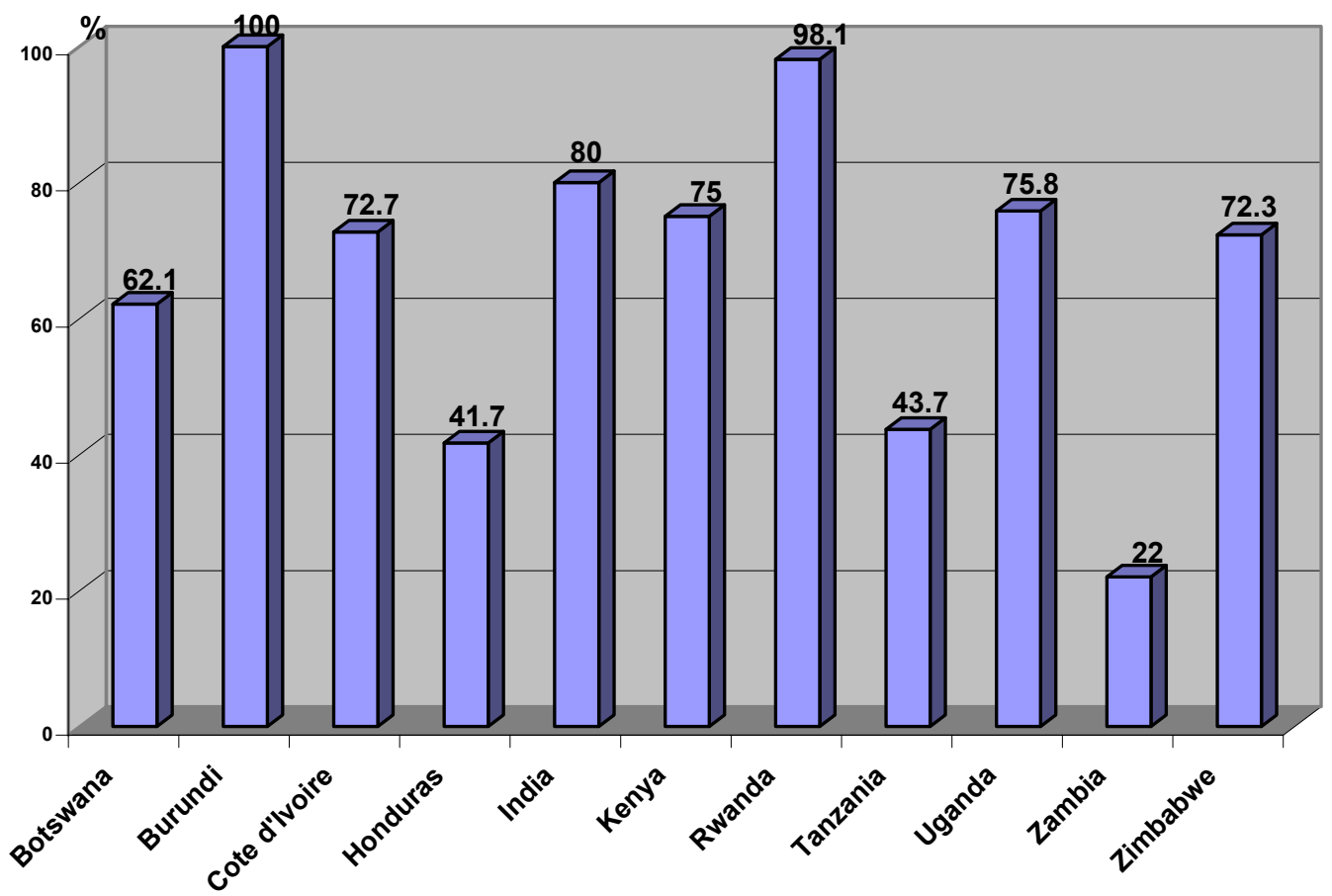

Source: UNICEF. PMTCT Programme News. November2002. Issue no. 4. HIV/AIDS Unit.

Finding: Including HIV tests as part of routine antenatal care increases the proportion of women who are tested but significant minorities do not collect test results.

One striking finding of the evaluation is the consistency across countries in the percentage of women who accept an HIV test after counseling. With the exception of Botswana, this proportion ranges between 64 and 83 percent (see Figure 5). Although counseling quality is one key factor motivating women to take the HIV test, making the test a routine part of antenatal care is also important to encouraging women to be tested. Because most programs routinely draw blood from a vein for an antenatal syphilis test, the same blood draw can be used for HIV testing. However, relying on the routine blood draw has its disadvantages. Some of the ELISA and rapid HIV tests using blood drawn intravenously cause delays, which further complicate getting results back to women. By comparison, tests using finger pricks give results in a few minutes. 


\section{Figure 5: Percent of ANC Clients Who Had an HIV Test after Pretest Counseling PMTCT Pilot Sites, January 2000 through June 2002}

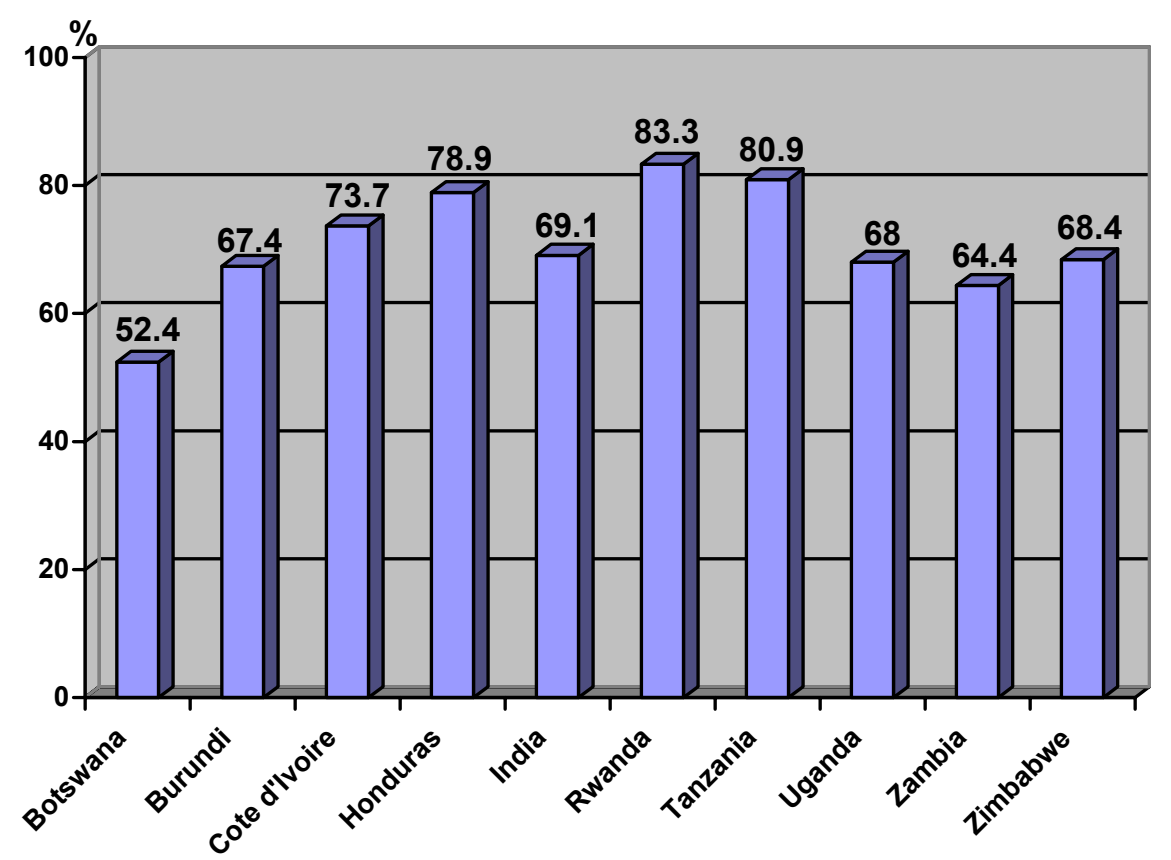

Source: UNICEF. PMTCT Programme News. November 2002. Issue no. 4. HIV/AIDS Unit.

Programs do not routinely report the proportion of women who make the effort to collect their HIV test results, but special studies from Zambia and Kenya give some insight. In Zambia, at a large urban health center in Lusaka which used rapid tests but often did not have results available the same day as the test, only 37 percent of women collected their test results; by contrast, at a rural clinic where the counselors offered antenatal care through outreach services at health posts, and performed rapid HIV tests as part of their one day visit to the site, almost all clients received results. At the other four pilot sites in Zambia, the proportions ranged from 57 to 78 percent. HIV-positive women in Zambia were more likely to collect their results than those not infected. At two sites in Kenya, just under threequarters of women collected their HIV results.

Why would a woman have an HIV test and then not receive the result? Women change their mind after agreeing to the HIV test or may have acquiesced to the health workers recommendation to have an HIV test without being convinced of the benefits. Test results are frequently delayed and women give up waiting for them, are told to come another day, or deliver before results are ready. If they have relatively little interest in finding out their HIV status, they might not want to go to the trouble of returning to the clinic or inquiring on their next visit. Also, many women agree to the test but then want to consult with their husband before receiving the results. Some husbands may object to their wife knowing whether she is infected. And some women have economic reasons, such as lack of money for transportation to return to the clinic.

Finding: $\quad$ ARV provision is working well, but coverage remains a challenge 
Provision of ARV in the $\mathrm{MCH}$ setting has been relatively simple and problem free but the drugs are still not reaching many pregnant women. In nine of eleven pilot countries only between 40 and 60 percent of women who test positive for HIV at the PMTCT site get ARVs (see Figure 6). Provision of ARVs is notably less in Cote d'Ivoire and Zimbabwe (24 and 34 percent, respectively, of women who tested HIV positive received ARVs). ARV protocols vary according to program experience and client characteristics. Cote d'Ivoire, Honduras, and Zimbabwe have provided mainly zidovudine; India and Rwanda are currently only using Nevirapine (provided in the labor room in India and to women who are near term in Rwanda); and the other pilot programs provide one or the other, depending on the characteristics of the site and clients. For example, in Homa Bay, Kenya, the choice of ARV is based on how far along the woman is in her pregnancy at the time of testing and where she expects to deliver her baby. Women who know their HIV status before the thirty-fourth week of pregnancy receive zidovudine if they plan to deliver in the hospital; women who know their HIV status before thirty-four weeks receive Nevirapine if they do not plan a hospital delivery or live very far away; women who learn their HIV status after thirty-four weeks are given Nevirapine. 


\section{Box 1: Feasibility studies of short term AZT and NVP interventions to prevent PMTCT of HIV in India}

The PMTCT pilot project using short course AZT was initiated in 2000 as a one year feasibility in 11 institutions or 'Centers of Excellence' across 5 high prevalence states in India: Maharashtra, Tamil Nadu, Andhra Pradesh, Karnataka and Manipur.

The AZT study concluded that it was feasible and cost effective to integrate PMTCT services into existing $\mathrm{MCH}$ services. However, while almost $90 \%$ of the women attending the antenatal clinic received group counseling for primary prevention and $53 \%$ accepted being tested, of the HIV positive women $(1.7 \%)$ only $44 \%$ received the AZT intervention.

A feasibility study with NVP was initiated in October 2001 in the same 11 institutions where the AZT feasibility study was conducted previously. The NVP feasibility study was initiated without any of the initial lag period experienced in setting up infrastructure and training counselors as seen at the time of the AZT study.

The decision to scale up was taken after a midterm analysis (6 months) of the NVP feasibility study results revealed an improved coverage with $92 \%$ of women accepting testing and $72 \%$ of HIV+ mothers (and their babies) receiving Nevirapine.

HIV-positive women at the pilot sites did not receive a complete course of ARVs for a variety of reasons, including: having not yet reached thirty-four or thirty-six weeks gestation when zidovudine is initiated and not coming back after; not taking the full dosage of their ARV; partner opposition; concern about taking drugs in pregnancy; delivering at home or at another facility and thus missing out on the intrapartum doses; or reaching the health facility when in active labor and thus too late for intrapartum doses. Where programs dispense zidovudine for women to take at home, there are additional reasons for not receiving ARVs: some women do not return for antenatal visits in the last month of pregnancy; others become anemic and have to stop taking zidovudine; and still others deliver prematurely or miscalculate their due date and deliver before they can receive ARVs. To increase use of ARVs, programs are switching to or relying more heavily on Nevirapine; giving women Nevirapine to take home with them and ingest at the onset of labor; emphasizing the importance of taking the ARVs as prescribed; and encouraging women to deliver in a health facility where health workers can provide or monitor adherence to the labor dose of ARVs. 


\section{Figure 6: Percent of HIV-Positive Pregnant Women with an HIV Test Who Received Prophylactic Antiretroviral Drugs, PMTCT Pilot Sites, January 2000 through June 2002}

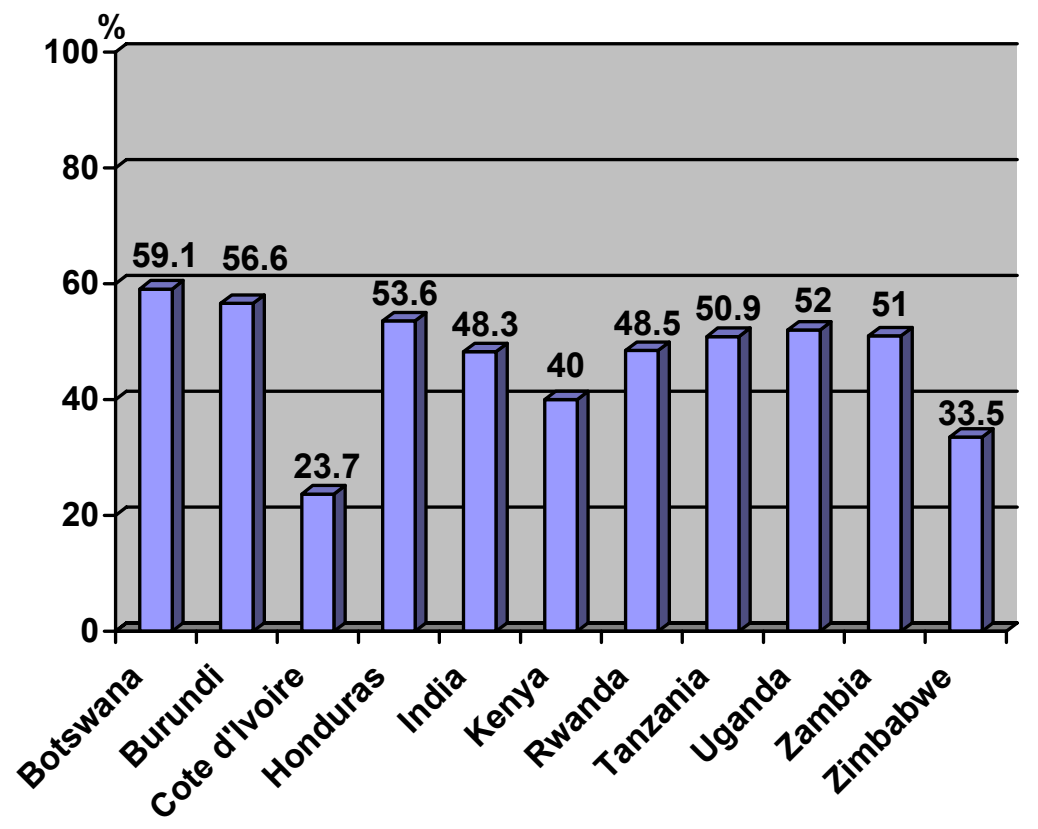

Source: UNICEF. PMTCT Programme News. November 2002. Issue no. 4. HIV/AIDS Unit.

One measure of the effectiveness of PMTCT programs is the proportion of all HIV-positive pregnant women attending antenatal clinic who get the ARV drugs. Viewed from this standpoint, the pilot results are troubling. As Figure 7 shows, in most countries, one-quarter or fewer of HIV-positive pregnant women receiving antenatal services ultimately get a short course of ARVs. This reflects missed opportunities at each step along the way: in pretest counseling, HIV testing, post-test counseling and results given, and in the provision of ARVS. Although ARV provision is still too low, recent data show an encouraging increase. While slightly more than 20 percent of HIV-positive pregnant women received ARVs at the pilot sites in 2001, by 2002 this proportion had risen to 35 percent. 


\section{Figure 7: Percent of HIV-Positive Pregnant Women who Attend ANC Who Received Prophylactic Antiretroviral Drugs, PMTCT Pilot Sites, January 2000 through June 2002}

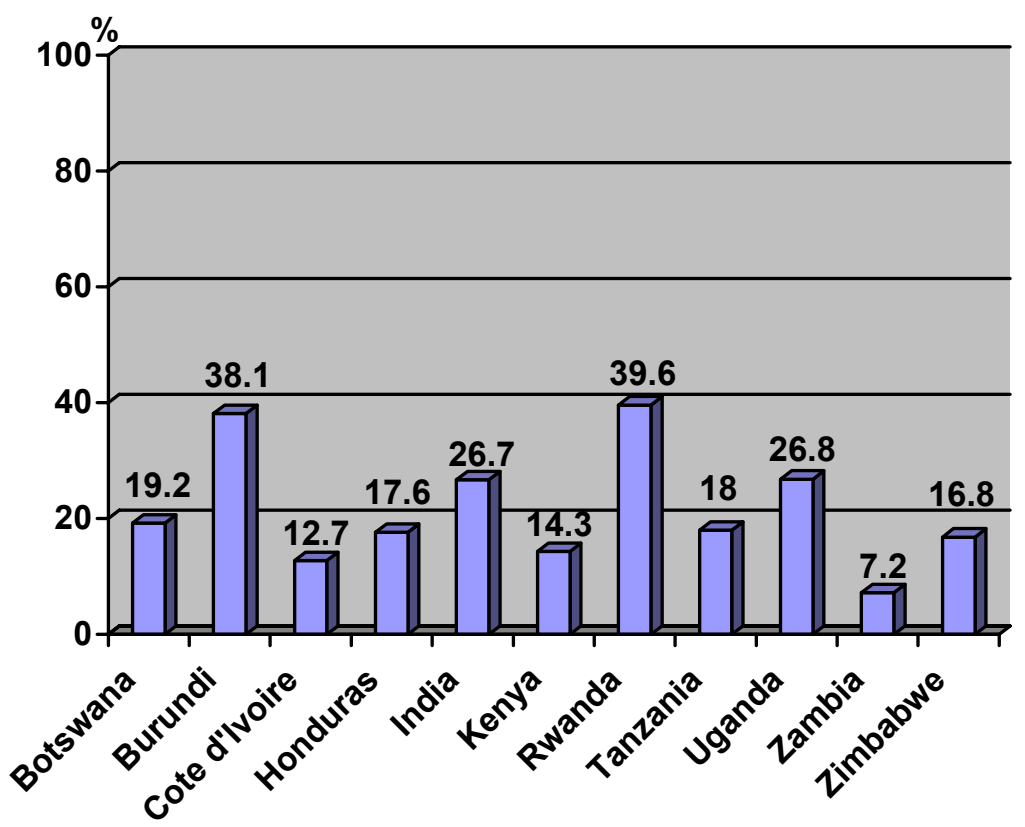

Source: UNICEF. PMTCT Programme News. November 2002. Issue no. 4. HIV/AIDS Unit.

A small number of pilot sites have actively followed up mother-infant pairs as part of operations research or extended evaluation. The limited data available show that the PMTCT services are effective in reducing in utero and early postnatal transmission among those women who receive the interventions. For example, in the pilot study in India, the rate of mother to child transmission in utero and at delivery was estimated to be 8 percent when the mother received zidovudine, and the rate of transmission in utero and the first two months of life was also estimated to be 8 percent when the mother and infant received Nevirapine.

The supply of ARVs has not been a problem in the study sites, however, basic essential MCH drugs and supplies were reported to be in short supply at many sites. As with other components of the PMTCT program, the supply component should be integrated into existing systems. For scaling-up access to services including ARVs for PMTCT, there are no alternatives to using the existing supply systems and programs are vulnerable to being constrained in scaling-up because of the weakness of current systems.

\section{Finding: $\quad$ The benefits of PMTCT go beyond the ARVS provided}

The PMTCT programs have greatly increased the amount of health education on HIV/AIDS and PMTCT, and specifically, information on how to prevent transmission provided to women and program evaluations show knowledge is increasing. For example, the proportion of pregnant women at the PMTCT pilot sites in India who knew how to avoid acquiring HIV/AIDS increased from 50 percent before receiving PMTCT counseling to 85 percent after counseling, and the proportion who 
knew how to avoid mother-to child transmission increased from 36 to 88 percent. PMTCT services are providing information to clients that is tailored to their concerns about and context of their own risk, the health of their partner and children, and their relationship with their partner. Interviews with clients in Rwanda and Zambia reveal that though sometimes the information is confusing or incomplete, nonetheless, it is empowering. PMTCT clients reported that: "...I got information I did not know," "I liked the message about MTCT to avoid infecting my baby," and "I now know even if I was HIV positive I could still live a normal life unlike when I only knew HIV is death." Women learn they are not helpless to respond to HIV.

\section{Finding: $\quad$ A PMTCT Health Information System is a critical management tool}

Creating and maintaining a health information system than collects the above information on the number of women utilizing various PMTCT services is critical. Such data are essential to monitor and evaluate the volume of services provided, program coverage, how successful the program is at reaching women in need and where bottlenecks or breakdowns within services occur. This information is an important management tool for planning, budgeting, monitoring and evaluating PMTCT programs.

\section{C.2. Factors Contributing to Program Achievements}

This section looks more closely at some of the underlying reasons for the initial success of many PMTCT programs, focusing on those aspects of the program that have performed especially well. These include motivated program staff, relatively good quality of care, adequate provision of antiretroviral drugs, and successful attempts to address stigma.

\section{Finding: Motivated health workers are the backbone of PMTCT}

PMTCT programs empower staff to respond to HIV Health workers are key to making PMTCT programs work. Particularly in the worst affected countries, communities look to the local clinic staff as the leading edge against the HIV epidemic. Until very recently, however, most health workers have lacked the training and skills to effectively provide PMTCT information and services to women. PMTCT pilot programs have now trained nearly 3,300 health workers, on topics that typically include the minimum package for PMTCT, general counseling skills, infant feeding counseling, and laboratory tests.

The introduction of PMTCT services has provided extra motivation and empowered health providers by — for the first time for many - giving them tools to help clients and their babies fight HIV. This has raised the status of clinic staff in the eyes of their clients and communities, reduced staff's frustration with how to help AIDS-affected clients, made them more supportive of AIDS-affected clients, and encouraged them to fight stigma against HIV-positive women in the clinic setting.

In response, many staff are putting extra effort into the care they offer their clients, for example, by providing after-hours counseling and support to mothers living with HIV.

Training can encourage and reward Successful programs recognize and address the needs of their staff for information, to ask questions, and to be supported. In Honduras, for example, managers have 
effectively capitalized on the cultural value that is attached to training and the enhanced status that trained workers perceive. The program effectively uses training to motivate and reward, providing highly-valued certificates to recognize completion of training.

Good management motivates staff Where site management is strong and health workers are committed to PMTCT goals, the program can be extremely effective. At the Kicukiro Health Center in Rwanda, for example, the enthusiastic director strongly promoted the PMTCT program and galvanized her staff to do so as well. In Kicukiro, all women visiting the ANC clinic were counseled on HIV and 86 percent were tested for HIV (see Table 1).

Table 1: PMTCT Program Statistics, Kicukiro Health Center, Rwanda, April 1999 - June 2002

\begin{tabular}{|l|l|l|}
\hline Service & \# Women & Result \\
\hline ANC Visit & 6171 & \\
\hline Counseled & 6171 & $100 \%$ of ANC \\
\hline Tested & 5299 & $86 \%$ of ANC \\
\hline HIV-positive & 1219 & $23 \%$ of ANC \\
\hline Zidovudine or Nevirapine provided & 768 & $63 \%$ of HIV + \\
\hline
\end{tabular}

Source: Report on the Rapid Assessment of the UN-Supported PMTCT Initiative in Rwanda, 2002

Finding: Levels of quality of care in PMTCT programs are encouraging.

HIV/AIDS counseling is appreciated and provides hope Information provided to clients is a very important element of quality care. PMTCT services are tailoring information to respond to client concerns about their own risk, the health of their partner and children, and their relationship with their partner. Although sometimes the information is confusing or incomplete, it is nonetheless empowering. Women learn they are not helpless to respond to HIV and no longer have to live with the fear of not knowing their infection status. They can choose to have an HIV test. A negative result and the vast majority of women are negative - is an enormous relief. When women find out they are infected, they know they can take action to keep their baby healthy and take concrete steps to improve their health and quality of life. Interviews with clients and community members in communities where PMTCT services are offered in Zambia found a widespread appreciation for PMTCT services (see Table 2). 


\section{Box 2:. What Zambian Clients Say About the PMTCT Program}

"I have hope for a healthy baby"

"I got information I did not know"

"I received more information on HIV"

"I am now confident of my status"

"I am no longer afraid"

"I now know even if I was HIV-positive I could still live a normal life, unlike when I only knew HIV is death"

Counselors are "like a friend;" "attentive, well-intentioned, and understand our problems"

"It's between the counselor and the client. Discussions are buried in the office. It's a secret between the two of you."

Providers are taking action to ensure confidentiality The client-provider relationship is another element of quality that is key to program success. Effective PMTCT requires that all health workers caring for a client know that client's HIV status. PMTCT programs have successfully put in place new systems to ensure confidential sharing of HIV status within MCH settings. These include codes on the ANC card allowing health workers to share clients' HIV status among themselves without violating privacy.

\section{Finding: PMTCT programs contribute to stigma reduction}

While most PMTCT programs report experiences with stigma in health care settings and in communities, generally clients and program managers do not highlight stigma and discrimination as a major program challenge. ${ }^{4}$ Similarly, the evaluation found no evidence from program staff that the introduction of PMTCT programs in the $\mathrm{MCH}$ setting has discouraged use of traditional antenatal care. Statistics showing no downward trend in clinic attendance at the pilot sites corroborate these perceptions.

Participation in the PMTCT program may expose some HIV-positive mothers to potential stigma by presenting visible markers of her HIV status. For example, focus group respondents in Zambia report that people at times conclude that new mothers are HIV-positive because they may stop breastfeeding early and/or receive food from the PMTCT program. In Tanzania, boxes of formula were reported as markers of HIV infection. Persons found to be HIV-positive could be mocked (ironically, even by other infected people), isolated from others, or shunned by families.

\footnotetext{
${ }^{4}$ The need for the PMTCT program to address stigma against people living with HIV/AIDS was mentioned in interviews with key informants in Kenya, Tanzania, Uganda, and Zimbabwe.
} 
Fear of stigma dampens demand for services. Many women fear that their husband or partner will react badly if they find out they have been tested or-even worse-bring home news of a positive result. One female focus group participant in Zambia describes how some husbands respond to a wife who tests positive: "Some men would refuse to accept the result and chase their wives, saying 'go back to the clinic, the disease is yours, not mine." As noted above, when asked why they do not collect their test result, women often cite "husband's reaction" to being tested without his permission and to a positive result.

While fears continue to dampen utilization of PMTCT services, the actual experience of services users in selected settings for which we have data has been mainly positive. An analysis of the experience of HIV testing and disclosure among PMTCT clients from two pilot sites in Kenya and one pilot site in Zambia found that the majority of women experienced positive outcomes of disclosure of their HIV serostatus, with a relatively small proportion of women reporting adverse events with partners (Synergy, 2003). Women who were seronegative are more likely to disclose, but there is no systematic relationship between HIV status or disclosure and adverse events. The study findings suggest that women are likely to self-select for VCT knowing that it is safe for them (based on their best estimate of their partner's potential reaction). Those who tested and received their results and who disclosed to their partner are perhaps the women who felt the safest. The findings also suggest the benefits of even the brief amount of counseling provided in the PMTCT programs, as rates of disclosure were much higher among these groups than previous reported for antenatal settings which were running clinic trials rather than integrated PMTCT programs.

In client interviews with nine HIV positive clients interviewed at the two sites in India, one reported that her husband had absconded. On the other hand more than half of them reported receiving active support from in-laws (even when some had lost their husbands) as well as their husbands. A client who had just delivered the day before and received NVP had her in-laws by her bedside; the motherin-law was advocating replacement feeding. A second client was accompanied by her HIV-positive husband, who made it a point to come to every follow up visit, and a third client, was always accompanied by her father in law. The promise of a healthy child or grandchild may be a contributing factor.

Focus group participants reported increasing support and sympathy for people living with HIV/AIDS. Examples of stigma reduction include reports of supportive relatives and community members living openly with HIV/AIDS. Compared to urban communities, rural areas in Zambia appear to be more supportive of and less likely to stigmatize an HIV-positive woman.

PMTCT programs contribute to stigma reduction and reinforce other AIDS awareness and prevention activities by fostering couple and community discussion on HIV and by normalizing HIV counseling, testing, and care. The following examples illustrate the positive effect PMTCT programs are having:

- A community health leader in Rwanda believes that perception of HIV-positive people has changed because now "people consider HIV-positive persons as sick people like others. They share food and beverages together without being afraid."

- A young woman in Rwanda notes the problem of self-stigmatization: "Someone who is sick will consider himself as socially unacceptable. Ways to help those people are to be found. If sick people are marginalized they will involuntarily contribute to the spread of HIV." 
- A male focus group participant, also in Rwanda, suggests that, "the community and, above all, the health educators, should encourage people to get tested, and pregnant women to get tested so that if they are positive, they can receive a healing for mother-to-fetus transmission risks."

- In Zimbabwe, a key informant notes that PMTCT and VCT programs help bring HIV issues out into the open.

- Officials in India's PMTCT program say that one of their greatest successes has been the improvement in the attitudes of clinic staff towards people living with HIV/AIDS.

- At two PMTCT sites in Kenya, program staff, UNICEF and Maendeleo ya Wanawake (a national woman's organization) combat stigma by training peer counselors among HIVinfected women (and, in one instance in each site, a spouse).

\section{C.3. Program Challenges}

While the previous section looked at facets of the PMTCT pilot that are performing relatively well, this section focuses on some of the serious remaining challenges in the areas of communication, male involvement, infant feeding counseling, care and support, and basic provision of antenatal, family planning, and primary health care.

\section{Finding: Communication activities to mobilize communities lag behind clinical services}

A framework for development of integrated PMTCT communication strategies provides a strong base to address key PMTCT-related issues such as primary prevention of HIV; uptake of PMTCT interventions such as VCT, ARVs, and recommended infant feeding practices; involvement of men, youth and persons living with HIV/AIDS (PLHAs); community-based care and support; and stigma and discrimination. However, the additional management and resource burden of developing and carrying out a communication strategy has delayed or limited the implementation of such strategies in many sites. As of mid-2002, five of the eleven pilot programs had developed and disseminated their communication strategy, four others had partially developed and/or implemented a strategy (for example, where the program has developed materials for women attending PMTCT services but not materials for the wider community or has completed development of a strategy but not yet disseminated it), and two programs were just beginning their strategy development.

The communications strategies contain some combination of the following elements and activities:

- meetings with opinion leaders such as parliamentarians, local officials, and local community leaders to advocate for the PMTCT program;

- $\quad$ videos, talks, leaflets, brochures, posters, radio and television broadcasts, drama, song, and press releases to inform providers, clients, and the community about PMTCT and how it can be prevented; and

- social mobilization aimed at building confidence, trust, respect, and ownership of the PMTCT program and providing support to those already infected.

The pilot programs have generally concentrated first on communications within the clinics to provide materials for providers, clients, and their families. Partly this is because activities in the community are more challenging to sustain. Unlike clinic educational materials, which have a reasonable shelf 
life, drama, song, radio, and other communications targeted at the broader community require constant production and funds. Pregnant women have been the main beneficiaries of these initial efforts and many key informants mention the need to expand their communication activities to better reach men and the broader community. For example, community members in Zambia would like to see more information and education taking place within their community, not only in the clinic as is the case currently. Equally, programs need to do more to sensitize the community to reduce stigma for HIVpositive individuals. The community sees itself as having a role to play within PMTCT programs. Some community workers, volunteers, and PLHAs want programs to ask them to mobilize the community, and to pay them for the effort. Both HIV-positive mothers and community members identify peer support groups as an effective mechanism for mobilizing the community around PMTCT, reducing stigma, and supporting PLHA. However, as of mid-2002, only the programs in Kenya and Zambia had introduced this strategy.

\section{Finding: Attention to engaging male partners is insufficient}

In most of the pilot settings, male involvement and support is critical to improving women's uptake of core PMTCT services including the decision to test; returning for test results; correctly taking ARV drugs; and choosing and carrying out an infant feeding method. Male involvement is also critical for primary prevention of HIV and avoiding unintended pregnancy. Nonetheless, pilot programs have done relatively little to involve men. Program managers in all eleven pilot sites identify male involvement as weak. This neglect has contributed to the lower-than-hoped-for uptake of the program in many areas.

Expectations and impacts of male involvement vary across countries. In the low-HIV prevalence setting of Honduras, lack of male involvement does not greatly inhibit women's use of PMTCT services, but is an important obstacle to negotiating safe sex and preventing unwanted pregnancy. Male involvement is still a new concept in Indian society, which sees antenatal care and childbirth as traditionally a "women-only" activity.

The pilot experience highlights how antenatal clinics are generally regarded as women's spaces where men do not feel comfortable. In Burundi, for example, the VCT center for the community shares space with the PMTCT program. The community perceives the VCT center as part of ANC services, and thus it attracts few men. Most programs expect women to communicate information to their partners, yet this is often difficult given societal norms about gender roles. As one mother in a group counseling session in Zimbabwe notes, "As we sit here some of us know how difficult it is to ask our partners to come for testing. As long as society continues to condone infidelity we will never win the war against HIV infection. Some men disappear from home for a number of days and on coming back they become very aggressive to make sure the wife does not ask a lot of questions."

Many program managers see encouraging male involvement as one of their greatest challenges. They recognize that male involvement is weak in part because few program activities are male focused. Where programs have been successful, they have concentrated on providing information directly to men and located these communication activities for men outside of the antenatal clinic. The following examples from Zambia and Kenya illustrate these approaches. 
- In Keemba, Zambia more than 40 percent of male partners of women in the PMTCT program have undergone HIV counseling and testing. In addition to the general strategy of community mobilization strategy, program staff talk about PMTCT directly with male leaders rather than through women. They also listen to the men's concerns. For example, one community leader was worried about the risk of HIV infection for himself, his wives, and his sons, and asked the staff from the PMTCT program to give a talk to his extended family. He and a number of his wives subsequently came for VCT. Several other men and their wives later followed his lead and got tested. A number of facilities in the area provide VCT, including the outpatient clinic, which provides men with comfortable access to VCT, the antenatal clinic to which they send their pregnant wives, and rural health posts during outreach visits using rapid tests.

- From the outset, Kenya PMTCT program managers identified the need to involve male partners as a critical program element. Strategies for informing male partners about PMTCT services and encouraging their support include inviting men to the clinic for HIV counseling and testing, community education on PMTCT in places where men congregate, and support groups for men. These strategies led to a significant increase in discussions about VCT and PMTCT between PMTCT clients and their regular partners, HIV testing among male partners of PMTCT clients, and disclosure of HIV results by both women and men to a regular partner (see Figure 8).

Figure 8: Impact of PMTCT Male Involvement Strategies on Partner Communication in Kenya

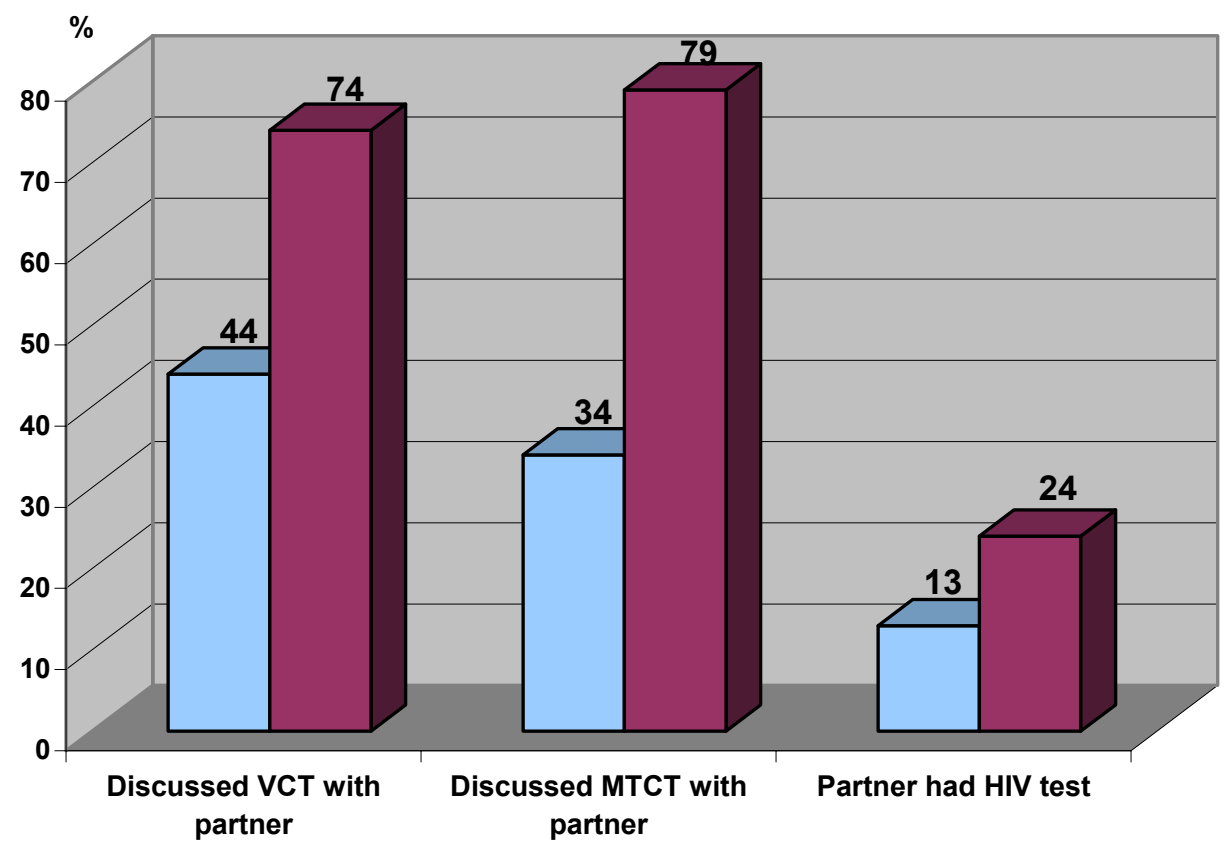

口Before PMTCT program $\square$ With PMTCT program 


\section{Finding: Infant feeding remains the most challenging component of PMTCT programs}

Infant feeding counseling and support which address the special needs of HIV-positive women has proved to be the most demanding component of PMTCT programs. Major challenges in this area include:

- the development of locally applicable guidelines;

- changing health worker behavior;

- $\quad$ supporting women's infant feeding choices after they give birth;

- encouraging and monitoring adherence to the choice of exclusive breastfeeding or replacement feeding; and

- evaluating the impact and effectiveness of infant feeding counseling.

National Policy Development. Global guidance for HIV and infant feeding counseling exists, but each country needs to assess the feasibility, acceptability, affordability, safety, and sustainability of replacement feeding and to develop or adapt policy and guidelines based on that assessment. At the time of the evaluation, seven of the eleven pilot countries had developed national guidelines for infant feeding which include recommendations for HIV-infected women.

Health Workers and Training. Nurse-midwives typically do most infant feeding counseling, although countries such as Cote d'Ivoire employ infant feeding or lactation counselors, and Rwanda counsels women at separate nutrition centers. Each of these options has advantages and disadvantages. Using nurse-midwives virtually guarantees a high level of integration of counseling with other $\mathrm{MCH}$ services, since nurse-midwives counsel at the same time they offer other services. However, the added duty can overload the nurse-midwife. Infant feeding or lactation counselors - who may be professional, lay, or peer counselors - generally have a greater level of expertise on infant feeding than the typical nurse-midwife. But the specialized counselor tends to be less well integrated with the rest of PMTCT care. Use of a freestanding nutrition center, as in Rwanda, expands program partners and thus spreads the workload. But, again, links with other PMTCT services are weak.

Five pilot countries - Cote d'Ivoire, Tanzania, Uganda, Zambia, and Zimbabwe - offer separate trainings on lactation counseling and HIV and infant feeding, while six other pilot countries integrate infant feeding counseling into PMTCT training. In Rwanda and Zambia, only a minority of PMTCT program staff (four of seventeen workers interviewed in two sites in Rwanda and eighteen of fortyeight providers interviewed in Zambia) had been trained on infant feeding and counseling. At a third Rwandan site, although the site manager reported that all staff members had either attended a formal PMTCT course that included instruction on infant feeding counseling or received training from a fellow staff member, staff knowledge of infant feeding was low. Most providers did not clearly understand the advantages and disadvantages of the various feeding methods presented for reducing HIV transmission through breastfeeding: exclusive maternal breastfeeding for six months and then abrupt cessation, wet nursing, milk banks, expressed and heat-treated breast milk, and home-prepared formula made from modified animal milk. Nor could most providers cite all the strategies (for example, breastfeed exclusively, correct positioning, feeding on demand) that would optimize the advantages of breastfeeding, in general, and might minimize the risk of transmitting HIV through breastfeeding. Detailed information on health workers' knowledge of infant feeding is not available for other sites. However, the large number of PMTCT providers that need training and the high staff 
turnover and rotation make it likely that many programs struggle with ensuring that there are not similar gaps in knowledge in their programs.

Counseling and support. PMTCT programs are not adequately equipping their clinic staff to discuss the benefits and risks of breastfeeding and other local infant feeding options and whether replacement feeding is acceptable, feasible, affordable, sustainable, and safe.

Observation of services in Honduras, India, Rwanda, and Zambia found that program staff generally only mention a few kinds of replacement feeds (formula, modified animals milk, and heat-treated expressed milk) and counseling for HIV-positive women often promotes one feeding method over others. This may occur because many of the options presented in guidelines and during training are unfamiliar or unacceptable in the local setting. For example, when asked "What are your opinions about HIV-positive women who do not breastfeed?" twenty-eight Zambian providers said the woman is doing the "right thing," one had a negative opinion of this behavior, and seven were neutral. When asked whether they thought there was one best infant feeding method for HIV-positive women, twenty-one providers replied formula, one replied exclusive breastfeeding for six months, and ten said there was no best method - each had advantages and disadvantages. The responses were unrelated to whether the health worker had received training on infant feeding counseling.

In India, all of the counselors interviewed believe that exclusive breastfeeding is the best choice for all women, regardless of HIV status. The low socioeconomic status of women using public sector services in part influences this view. Modified cow or buffalo milk is the only replacement feed that programs discuss as an option. Officials are reluctant to promote or offer formula to poor, uneducated women, only discussing formula with those women specifically requesting it and who appear to be able to afford it. Counselors rarely discuss other choices such as heat-treating expressed breast milk or wet nursing.

\section{Box 3: Infant Feeding Counseling and Support in Zambia}

Information from counseling observations and exit interviews in Zambia sheds light on some of the strengths and weaknesses of the infant feeding component of the PMTCT program. Based on observations of forty-two infant feeding counseling sessions, counselors provide a considerable amount of information. Counselors almost always discuss the advantages and disadvantages of exclusive breastfeeding for three or six months then abrupt cessation and formula (two options recommended by the Zambia program). Counselors mentioned expressed heat-treated milk and modified animal milk in about one-third of sessions, and wet nursing in five sessions. Yet in the majority of sessions, counselors failed to ask key questions necessary to help the woman consider her ability to carry out alternative feeding choices. As a result, providers frequently steer a woman towards an infant feeding method based solely on her HIV status rather than a comprehensive assessment of her social and economic resources for implementing various feeding options. For example, only ten of forty-two inquired whether the mother had money to buy formula and only six asked whether the client had access to adequate supplies of water and fuel. Just seven counselors asked whether the client had disclosed her HIV status to her partner and only five asked whether the client had disclosed her HIV status to other family members or close friends. 
In slightly over half of sessions (twenty-six of forty-two), the providers "adequately" explored (and in twelve sessions "somewhat" explored) the feasibility and acceptability of various feeding options. Every provider observed with the exception of one made suggestions rather than commands about infant feeding options. Half of the providers (twenty-one) "directly" addressed partner involvement in infant feeding decisions, less than half (twelve) did so somewhat, and one-fifth (nine) did not.

Analysis of sixty-nine client exit interviews shows that the counselors are providing convincing, sound, comforting information about optimal feeding choices and are helping women feel they have made a good decision - even if they have not made much of a decision but rather followed the lead of the counselor. Most women interviewed report that counselors had explained just one option (infant formula feeding was the most popular option, followed by breastfeeding). Nonetheless, a majority also reports that the infant feeding counseling session had helped them decide how to feed their babies. Thirty of the sixty-nine respondents say they had chosen formula feeding, while the rest had decided to breastfeed. Despite most women indicating that they did not receive more than one infant feeding choice, only fifteen reported that they felt the counselor was promoting one option over the others. As one client says, "I understand what it meant, that is why I chose infant formula." Fifty-four women say that the counselor had also discussed the safety of the chosen feeding method.

Ideally, programs should support women to carry out their infant feeding choice after their baby is born. However, the evaluation found very few examples of ongoing support provided by lactation counselors, breastfeeding support, or mothers' groups. This excerpt from the Tanzania Final Donor Report to United Nations Foundation Inc perhaps best summarizes this gap - uncovered in interviews with key informants from many programs - .:

The follow up component was the least successful—perhaps as anticipated — taking into consideration the weaknesses of post-natal care services in Tanzania as described elsewhere in this report. The client follow-up component is perhaps best placed with NGOs that have developed particular skills in homebased care and psycho-social care and counseling, and partnerships especially in this area need to be explored in the coming years.

Infant Feeding Practice. Breastfeeding and replacement feeding with either formula or modified animal's milk are virtually the only three options that PMTCT programs discuss and, presumably, the only ones that mothers practice. All of the pilot programs promote exclusive breastfeeding with early cessation for HIV-positive women who decide to breastfeed. Seven of the eleven pilots (Botswana, Burundi, Honduras, Cote d'Ivoire, Kenya, Uganda, and Zambia) provided infant formula to mothers.

Only where formula is provided by the program, and thus free, do large numbers of mothers use it. Otherwise, the high cost eliminates formula as a real option for most women. Many program staff and community members believe free provision of formula contributes to the credibility of the PMTCT program. In Honduras, for example, providers and stakeholders at regional and national levels repeatedly spoke about the importance of infant formula as part of the PMTCT program. The decision by UNICEF to cease procurement and donation of formula after February 2003 has presented a challenge to the Honduras program, prompting the inter-institutional PMTCT committee to request that the government assume responsibility for the free provision of formula. Health workers at one site express serious concern that if formula cannot be provided free of charge, the program will lose 
credibility, and their motivation to support PMTCT will decrease sharply. Clinic staff in Rwanda and Zambia express similar sentiments.

Adherence to either exclusive breastfeeding or replacement feeding is a challenge for any mother. Information on feeding practices from Botswana, Kenya, and Zambia give some insight on how well mothers adhere to guidelines (see Table 3). ${ }^{5}$ The highest level of adherence to the recommended feeding options for HIV-positive mothers is seen in Botswana, where 90 percent of HIV-positive mothers fed their babies only breastmilk or only formula in the previous twenty-four hours, followed by Zambia with 68 percent adherence and Kenya with 38 percent adherence. ${ }^{6}$ Within this very small set of observations, levels of adherence corresponded with the socioeconomic levels, suggesting that access to resources, including women's education and autonomy, play a key role in adherence. Most HIV-infected women in Botswana give infant formula; of the fifteen women who say they intended to breastfeed, only four managed to do so exclusively. HIV-negative women in Botswana were the least adherent to the recommended feeding practice of exclusive breastfeeding for children less than six months of age, with only 17 percent reporting exclusive breastfeeding, compared to 28 percent in Kenya and 57 percent in Zambia.

Table 2: $\quad$ Infant Feeding Practice Following the Introduction of PMTCT Programs in Botswana, Kenya, and Zambia, 2001-2002

\begin{tabular}{|c|c|c|c|}
\hline \multirow{2}{*}{$\begin{array}{l}\text { Infant Feeding } \\
\text { Practice }\end{array}$} & \multicolumn{3}{|c|}{ HIV Status } \\
\hline & $\mathrm{HIV}+$ & HIV- & Unknown \\
\hline \multicolumn{4}{|c|}{ Botswana (infants 0-6 months old, based on 24 hour recall) ${ }^{\text {a }}$} \\
\hline Exclusive breastfeeding & $3 \%$ & $17 \%$ & $32 \%$ \\
\hline $\begin{array}{l}\text { Exclusive replacement } \\
\text { feeding }\end{array}$ & $87 \%$ & $6 \%$ & $8 \%$ \\
\hline Mixed Feeding & $10 \%$ & $77 \%$ & $60 \%$ \\
\hline $\mathrm{N}$ of Women & 158 & 157 & 186 \\
\hline \multicolumn{4}{|c|}{ Homa Bay, Kenya (infants 6 weeks old, based on 24 hour recall) } \\
\hline Exclusive breastfeeding & $24 \%$ & $28 \%$ & $24 \%$ \\
\hline $\begin{array}{l}\text { Exclusive replacement } \\
\text { feeding }\end{array}$ & $14 \%$ & $1 \%$ & $1 \%$ \\
\hline Mixed Feeding & $63 \%$ & $71 \%$ & $75 \%$ \\
\hline $\mathrm{N}$ of Women & 94 & 186 & 100 \\
\hline \multicolumn{4}{|c|}{ Lusaka, Zambia (infants 3 months old, based on 24 hour recall) } \\
\hline Exclusive breastfeeding & $44 \%$ & $57 \%$ & - \\
\hline Exclusive replacement & $24 \%$ & $1 \%$ & - \\
\hline
\end{tabular}

${ }^{5}$ Comparisons across countries must be made with caution. Data from the three sites includes children of different ages and socioeconomic groups.

${ }^{6}$ These estimates represent the upper limit of adherence. Data from these sites and elsewhere show that adherence calculated on the basis of responses to questions on having ever introduced other feeds results in lower estimates of exclusive breastfeeding. 


\begin{tabular}{|l|c|c|c|}
\hline \multirow{2}{*}{$\begin{array}{l}\text { Infant Feeding } \\
\text { Practice }\end{array}$} & HIV+ & HIV Status & Unknown \\
\hline feeding & & & \\
\hline Mixed Feeding & $23 \%$ & $41 \%$ & - \\
\hline N of Women & 71 & 210 & - \\
\hline
\end{tabular}

${ }^{\text {a }}$ In Botswana, women of known status were interviewed at PMTCT intervention sites; women of unknown status were interviewed at non-intervention sites.

Source: Botswana: Evaluation of Infant Feeding Practices by Mothers at PMTCT and non-PMTCT sites in Botswana, PMTCT Advisory Group, Report, 2001. Kenya: unpublished data from Kenya PMCT Project/Horizons cohort study. Zambia: unpublished data from MTCT-WG/Horizons study of cohort of women of known HIV status.

Spillover. Some observers have expressed concern that PMTCT programs that discuss replacement feeding for HIV-positive mothers may inadvertently cause other mothers who do not know their HIV status to avoid breastfeeding. This evaluation found little evidence of this "spillover" effect. The proportion of women of unknown status who are using replacement feeding, shown in Table 3, is a crude indicator of the extent of spillover. In Botswana, this proportion is eight percent (as compared to six percent of HIV-negative women) while only one percent of women of unknown status in Homa Bay, Kenya, a low-income area, report exclusive use of replacement feeds. Thus, women of unknown HIV status living in areas with a PMTCT program are not disproportionately using replacement feeds. More data are needed to confirm these encouraging results.

To minimize the possibility of spillover, PMTCT counselors in some sites in Honduras have developed a strategy of providing information on replacement feeding only during post-test counseling for HIV-positive women. Counselors encourage HIV-negative women to breastfeed exclusively, and deliberately do not mention that the program distributes infant formula for HIV-positive mothers. This strategy has been recommended as a national guideline. 
Monitoring and Evaluation. The monitoring and evaluation of infant feeding counseling and support is weak. All of the pilot programs track information on the infant feeding option selected by women in the PMTCT program either after counseling, during antenatal care, or at the time of delivery. However, the only information available about actual feeding practices is from special studies such as those in Botswana, Kenya and Zambia cited above. None of these studies observed the correctness of infant feeding practice (for example, breastfeeding attachment or preparation of infant formula). Additionally, scarcely any program experience documentation exists for developing practical guidelines and supporting mothers to cease breastfeeding over a short time period. Special studies in Botswana and India examine the impact of feeding practices on illness and death in infants. The results of the study in Botswana were used to develop and implement an accelerated action plan to promote, protect, and support infant and young child feeding. The plan includes policy development, enforcement of regulations for marketing breast milk substitutes, training of health providers, implementation of the Baby Mother Friendly Hospital Initiative, and communication activities. In India, a qualitative study of infant feeding practices showed that replacement feeding might be inappropriate for some mothers who were practicing it. A study of zidovudine feasibility showed that babies receiving replacement feeds are more likely to die. As a result of these studies, the PMTCT program in India is emphasizing exclusive breastfeeding.

\section{Finding: $\quad$ Programs recognize the importance of care and support but need more comprehensive services}

PMTCT pilot programs vary widely in the development of care and support services:

- Botswana has the most advanced care and support network. Women there have access to hospital resource centers staffed with nurses and social workers. These centers provide information and counseling to women, their partners, and the community at large; support groups for PLHAs; community home-based care and support groups; TB prophylaxis; and antiretroviral therapy for HIV-infected mothers entering the PMTCT program who meet medical criteria.

- One site in Kenya has the opportunity to refer women to a Médecins sans Frontieres clinic for ARV therapy for themselves.

- Most other pilot sites refer for treatment or prophylaxis for opportunistic infections.

- Many work with NGOs or community groups that provide psychosocial and material support and home-based care for HIV-infected women.

- Some have fostered post-test peer support groups.

Many key informants note that these are patchy efforts that need strengthening. The expansion of the MTCT-Plus Initiative ${ }^{7}$ will undoubtedly increase the opportunity for HIV care, particularly medical care for HIV-infected mothers.

\footnotetext{
${ }^{7}$ The MTCT-Plus Initiative supports the provision of HIV-specific care, including access to a number of standardized antiretroviral options when clinically indicated, to HIV-infected women and children identified in PMTCT programs, and to their HIV-infected family members as appropriate. For more information, see the mtctplus.org web site.
} 
As standard practice, all women are encouraged to bring their infants for immunization, questions about feeding and growth, and treatment for any illnesses. Whether mothers and infants return depends on the initiative of the mother. Often the children of HIV-infected women are seen elsewhere in the institution and the PMTCT program is not part of the follow-up. Most PMTCT programs planned to follow-up children for the first eighteen months of life to monitor sickness and death and to measure HIV transmission rates. However, this has not occurred except in specific sites, which were generally research settings (for example, in Cote d'Ivoire, India, Kenya, Uganda, and Zambia) or lowprevalence areas (Honduras, which also had a research component which provided PCR testing for HIV).

\section{Finding: $\quad$ PMTCT programs need to strengthen related antenatal, family planning, and primary prevention services}

While PMTCT programs have generally succeeded in introducing core services such as VCT and ARV provision into the $\mathrm{MCH}$ care setting, they have not made much headway in addressing related needs, including primary prevention of HIV in women, prevention of unintended pregnancy in HIVinfected women, and improved antenatal and obstetric care. Attention to prevention and treatment of sexually transmitted infections, maternal nutrition, and basic supplies for antenatal care remain inadequate.

Family planning is available at PMTCT sites, but not well integrated with HIV activities. For example, family planning counseling in Zambia is generally of good quality, with staff establishing good rapport with clients, explaining the advantages and disadvantages of the various methods, and demonstrating proficiency in providing family planning methods. However, family planning counseling failed to adequately address HIV issues. Of a total of forty-eight family planning sessions, health workers mentioned HIV transmission in twelve sessions, MTCT in only eight sessions, and HIV testing in nine sessions. That HIV transmission and unwanted pregnancy share some of the same risk factors was only mentioned in ten sessions, and dual protection through the use of a condom, as well as a family planning method, was only mentioned in sixteen sessions. In Rwanda, two of the three pilot sites are run by faith-based organizations that offer family planning counseling but do not provide contraceptives.

The lack of even basic syphilis screening is sometimes related to costs of these "additional" services. In Kenya, women have to pay for syphilis screening as part of cost sharing. In Karatina, a relatively well-off rural area, the program screens at least 80 percent of the antenatal women; about 2 percent test positive for syphilis. In Homa Bay, where 70 percent of the population live in poverty, 20 to 30 percent of the antenatal women are able to afford the test. In the absence of screening and treatment in this area, the prevalence of syphilis is approximately 20 percent.

In Rwanda, the Kicukiro Health Center has organized a comprehensive antenatal care and growth monitoring program for infants. Although the center provides the program during scheduled hours, a client can receive service even when she comes on a day that it is not offered. The center makes a special effort to accommodate clients who have traveled long distances. However, despite these efforts many women did not receive adequate information on danger signs during pregnancy, breastfeeding, replacement feeding, and family planning. 
However, programs still miss many opportunities for HIV prevention among HIV-negative women. Too little is done to ensure that those who have tested negative are encouraged to remain negative, for example, only two of eleven pilot programs offer additional post-test counseling for HIV-negative women.

\section{C.4. Scaling Up}

While improving access to and the quality of PMTCT services is a central concern, there is an urgent need to scale up the availability and coverage of PMTCT services to meet the needs of the millions of mothers already infected or at risk of infection with HIV. This section highlights key issues related to the success of scale up, including government support, high-level coordination, human resources, and a well functioning supply system. 


\section{Box 4: Botswana's Experience with Scaling Up}

In September 1998, a Cabinet Memo established the PMTCT program. The first step was the establishment of a Technical Advisory Committee (TAC) that was given the task to:

- define the package of PMTCT interventions;

- develop protocols and guidelines; and

- develop an implementation plan and submit a budget to the Ministry of Health.

The TAC comprised a broad range of stakeholders including representatives from government ministries and departments such as laboratory services, food and nutrition, and primary health care and key government partners such as WHO, UNICEF, CDC, and the Harvard AIDS Institute.

After an initial pilot phase, which was evaluated, the recommendation of the TAC was for gradual scaling up. However, a gradual approach was not politically acceptable. Within the next sixteen months Botswana achieved 100 percent coverage of PMTCT in all health districts, facilitated by:

- the development of a preparation package that included sensitization meetings with community leaders and communities, and decentralized district-level training carried out by a private institution that trained six trainers per district, who in turn trained the health workers;

- revision of the monitoring system, and integration with existing $\mathrm{MCH}$ registers and information systems;

- central procurement and distribution of PMTCT supplies including drugs, lockable cabinets, infant formula, and monitoring tools and integration with the Central Medical Stores;

- preparation of districts before launching the program including, at the district level, having at least one trained midwife counselor and PMTCT supplies in all clinics offering the service; and within hospitals, having at least two trained midwife counselors, one trained laboratory technician, one trained pharmaceutical technician and all supplies including laboratory equipment and reagents;

- linkages with other services, for example referral to an ARV clinic for HAART, and referrals for women counseled and tested outside government institutions.

The accelerated scaling-up process has caused a number of problems including weak referral, poor quality of counseling, counselor burnout, and the potential for spillover of formula feeding into the HIV-negative population. However, the dynamism created by the success of the scaling up process has allowed program managers to respond innovatively including supervision and mentoring of counselors, meetings to debrief counselors, refresher training, and counseling of counselors for management of the burnout syndrome; a new initiative that recruits and trains community workers to do take on some of the counseling burden; and a comprehensive infant feeding policy to actively promote safe infant feeding practices in the community. 


\section{Finding: Government support and high-level coordination is key as programs move from piloting to scaling up}

The complex and multisectoral nature of PMTCT programs demands strong leadership and good coordination to ensure the success of both pilot and scaled-up programs. PMTCT requires many types of institutions and individual skills drawn from government, technical resource experts, NGOs, PLHAs, and community representatives. Moreover, as international donors ratchet up their support for PMTCT, mechanisms need to be set up to coordinate these funds at all levels. A number of countries have taken steps in the right direction:

- In Cote d'Ivoire key organizational changes have opened up new avenues for PMTCT in the country. A ministry in charge of AIDS control became fully operational in late 2001; the country also established a new consultation forum on PMTCT with the participation of all national stakeholders.

- The Tanzania pilot program was initially hampered by the lack of ownership at the national level and the absence of a formal coordination body based at the Ministry of Health to collaborate closely with all partners, including government AIDS agencies, UN agencies, bilateral donors, NGOs and research institutions. After the ministry appointed an extremely proactive official coordinator for PMTCT in January 2002, the sense of ownership by the ministry of health increased rapidly.

- PMTCT officials in Uganda determined that strengthening government capacity to coordinate and run the program was critical for enhancing commitment and ownership. UNICEF now supports a full-time PMTCT staff person at the Ministry of Health. The increase in coordination has streamlined partnerships and averted duplication of efforts by the many partners working in PMTCT programs in Uganda.

- In Rwanda, a number of agencies independently launched PMTCT services. However, all agencies aim to have a common approach to PMTCT at all sites and have gradually streamlined the PMTCT model. The Treatment and AIDS Research Center (TRAC) has improved its coordination function, particularly in the areas of training, guidelines, and supplies, and agencies have joined together more to share information and resources.

This experience shows that the following factors are key to scaling-up PMTCT programs:

a. A PMTCT focal point that can advocate for the PMTCT program, mobilize resources, coordinate partners and provide ongoing support.

b. A coordinating mechanism for the relevant policy, technical and service delivery bodies to facilitate the development and implementation of common policies and guidelines and the sharing of information and resources.

c. A national plan that addressed devolution of critical program functions such as training, supervisions, monitoring and evaluation, and supplies.

d. Financial authority at all levels.

\section{Finding: Human resources will be critical in expanding coverage and scaling up}

A major challenge for many pilot programs is staff shortages. PMTCT programs are being introduced into health care systems that in many cases are already seriously under-staffed due to lack of 
resources, outflows of trained providers to private institutions or to other countries that offer higher salaries, and, possibly, AIDS-related mortality. PMTCT interventions — although designed to be part of routine services - create significant additional work for staff already discouraged by long-standing problems such as low pay and inadequate medical supplies. Despite the impressive number of workers trained, project sites are still short on staff — particularly trained counselors — with the skills to provide HIV-related care. Frequent transfer of trained staff exacerbates this shortage and leads to low productivity and worker burnout.

Key informants in nine of the eleven programs mention staff shortages or overburdened staff as a challenge to scaling up (in Burundi, the program is just beginning to scale up from the initial site; in Honduras, the relatively low HIV prevalence has meant less pressure on existing staff). As part of their scale up plan, Botswana has developed a Counseling quality improvement strategy which includes supervision and mentoring of counselors, refresher trainings, and counseling of counselors for management of burnout.

Scaling up will require resolving a number of human resource problems. Programs will have to carry out much more provider training and support. The current system of centralized training offered by the PMTCT program will not be feasible as programs scale up. Scaling up will require new models of decentralized and on-the-job training. Training by itself is not sufficient. To create a more enabling environment, programs will need to include managers in PMTCT training, reorient supervision to encourage support for front-line workers, disseminate PMTCT policies and procedures, and bolster the motivation of health workers through improving the availability of supplies, training on universal precautions, and post-exposure prophylaxis (currently only available to PMTCT providers in Cote d'Ivoire and some sites in India). Programs need to better monitor that those who are trained are providing PMTCT services. Finally, programs need to better estimate and budget for the costs of creating a cadre of trainers and training large numbers of clinic staff.

Building capacity for scaling up will also require sensitizing and engaging site, district and national managers to integrate PMTCT in all their management systems: planning, budgeting, supply, supervision, and monitoring and evaluation.

\section{Finding: $\quad$ ANC/MCH supply systems need strengthening to effectively integrate and scale up PMTCT services}

For scaling up access to PMTCT services, there are no alternatives to using the existing ANC/MCH procurement and supply systems for PMTCT supplies. If this chain is weak, the PMTCT program will be vulnerable to the same supply problems that beleaguer many $\mathrm{MCH}$ programs and strengthening this supply chain should be a priority activity. The supply systems underpinning the scale up strategy should be examined with attention to

- The selection of appropriate commodities

- Sensible procurement according to recognized principles

- Appropriate storage and distribution

- Ensuring the rational use by health workers and clients 


\section{Box 5: Key Scaling-Up Lessons}

A consultative meeting was held September 2002 in Mombasa, Kenya, to address scaling-up of PMTCT programs in high prevalence countries in Africa. The meeting participants identified a number of key lessons in considering scaling-up. These include:

- Recognizing that MTCT is not happening in a vacuum, and linkages need to and should be made to other programs such as SIP/SWAPS;

- Acknowledging that our role is not for us to want to do everything, but to ensure that those strategic linkages are made;

- The need for flexibility - knowledge and practice is ever changing;

- Partnerships -governments alone cannot scale up without this - but these have to be strategic with roles and responsibilities allocated carefully;

- Leadership is critical - at all levels;

- The initial uptake of MTCT services has been disappointing in many pilot sites. A common cause has been the lack of a comprehensive communication strategy especially with regard to community engagement. But it is clear that the quality and availability of counseling services are also important;

- The infant feeding dilemma which has confused many health workers and has probably led to the deterioration of support for breast feeding in many settings;

- The importance of ensuring that resources and supplies are planned far in advance and that the continuity of both is assured. It is therefore necessary to establish strong coordinating teams at the district and national levels to support the program.

Source: UNICEF. Draft Report of PMTCT Scaling Up, September, 2002, Mombasa, Kenya, UNICEF

\section{C.5. The Special Case of Low-Prevalence Countries}

As for other HIV/AIDS activities, strategies for PMTCT may vary depending on the stage of the epidemic. This section briefly examines the experience of PMTCT programs in low-prevalence countries.

\section{Finding: $\quad$ Programs in low-prevalence settings report similar experiences as high prevalence settings but also face unique opportunities and challenges}

Two of the pilots took place in relatively low prevalence settings in Honduras and India to learn how the introduction and scaling up of programs might differ in such a setting. The experiences in the lower prevalence sites have much in common with the higher prevalence sites in Africa though also significant differences. For example, documentation of the some aspects to the PMTCT program experience in India highlights that PMTCT services, including VCT, have been integrated into the antenatal care program quite successfully, despite several resource constraints at these sites. One factor contributing to the success, that was not present in most sites outside of India, was the addition of qualified counselors which ensured a high quality of counseling services overall.

India also differs from most sites in that resident doctors and nurses who rotate between departments with relative frequency and may not be up to date with the PMTCT intervention provide a significant 
proportion of PMTCT services. Ongoing hands-on orientation training for doctors and nurses may help with improving awareness of issues of pre- and post-test counseling, confidentiality, psychosocial counseling, and infant feeding counseling.

An operational difficulty identified in the AZT and NVP feasibility studies in India has been coverage for HIV positive women who choose to deliver at home, as is the case when they move away to their parental homes for the delivery. With the current program these women are ineligible and do not receive NVP. The India program should observe the experience in some sites in Africa where a NVP tablet is provided for the mother and syrup in a pre-filled plastic syringe stored in a dark or black plastic bag for the infant to be self-administered at home.

As seen elsewhere, the Honduran PMTCT program has rapidly established PMTCT sites and has many components that are working well. The enthusiasm to implement PMTCT services at site levels is demonstrated through committed providers. The simplification of the program (e.g. one ARV regimen and the way in which infant feeding counseling and services are provided) has contributed to the effective implementation at the site level.

Due to its low prevalence and small size of its target population, the PMTCT program has a number of characteristics making it different from both those in high-prevalence African countries and India. Because almost all clients are HIV-negative, VCT is less emotionally burdensome for both clients and providers. Client education and virtually routine HIV testing, as is done in Honduras, may be most appropriate in such a setting. The fewer absolute numbers of women testing HIV-positive means that programs are more likely to have the resources to provide individualized follow-up support. On the other hand additional advocacy for PMTCT is required, because HIV/AIDS is a lower priority health issue for governments in low-prevalence countries, and international donors have little interest in supporting programs compared to some high-prevalence settings. Moreover, knowledge of PMTCT within the health community is lower and fewer health workers are able to carry out PMTCT interventions.

\section{Conclusions}

The pilot experience has shown that introducing PMTCT programs into antenatal care in a wide variety of settings is feasible and acceptable to a significant proportion of ANC clients who have a demand for HIV information, counseling, and testing. These services are meeting that demand by providing HIV information that is tailored to women and mothers in a generally safe and supportive setting and empowering women to make decisions about HIV testing, broach the impact of HIV in their lives with their intimate partner, and take action to reduce the probability of HIV transmission to her infant.

In many aspects, however, programs can improve and expand to meet their objectives. First, while many women seek PMTCT services, the majority of HIV-positive women who attend antenatal clinics have not fully benefited - either because they never received HIV counseling, they declined testing, or they did not return for test results or ARVs. 
Second, while PMTCT programs have generally succeeded in introducing core services such as VCT, ARV provision, and counseling on HIV and infant feeding into the $\mathrm{MCH}$ care setting, they have not made much headway in addressing related needs, including primary prevention of HIV in women, prevention of unintended pregnancy in HIV-infected women, and improved antenatal and obstetric care.

Third, postnatal support and follow up of HIV-infected women and their infants to assist them with infant feeding, getting care for themselves and their families, and for monitoring and evaluating the program has generally been a weak program component and one that must be strengthened. Effective infant feeding counseling and support is one of the most challenging components of the PMTCT programs. A substantial proportion of HIV transmission from an infected mother to her infant takes place during breastfeeding. Gains made by the provision of ARVs will be greatly undermined if programs do not help clients adequately address the risk of transmission in the postnatal period. Major challenges in this area include the development of locally applicable guidelines; changing health worker behavior; supporting women's infant feeding choices after they give birth; encouraging and monitoring adherence to the choice of exclusive breastfeeding or replacement feeding; and evaluating the impact and effectiveness of infant feeding counseling.

Moreover, the benefit to the child of his or her mother receiving care from a PMTCT program will greatly diminish if the mother does not receive appropriate care and support for her own HIV infection that allow her to remain healthy and a strong caretaker for that child. Finally, data on the impact of the program in reducing mother-to-child transmission is a critical piece of information in planning and allocating resources for HIV programs.

The final challenge is to scale up PMTCT pilots into PMTCT programs. Scaling up means taking a program operating in pilot sites and expanding it to reach more people in more sites within a region or country. The ultimate goal of scaling up is to ensure that the largest possible number of clients have access to high-quality, effective PMTCT interventions. As noted above, scaling up is not only expanding to new sites but also expanding the scope of activities within sites to reach more women and to provide a comprehensive package of HIV prevention and care.

In their short lifetime, PMTCT pilot programs have offered services to hundreds of thousands of women. Just as importantly, their experience has served as a valuable learning opportunity. Because of their pioneering effort, the next generation of PMTCT programs will be better and bigger, thus helping many more women, children, and families.

\section{E. Recommendations}

Program recommendations discussed in this report are summarized here. The full set of PMTCT program recommendations arising from the evaluation of the UN-supported pilot experience can be found in Program Recommendations for Prevention of Mother-to-Child Transmission of HIV: A Practical Guide for managers (UNICEF and Population Council, 2003).

To increase coverage and improve infant feeding counseling: Experience at the pilot sites as well as from PMTCT programs elsewhere suggests several actions which may help keep women in the 
program to receive the full benefit of HIV and infant feeding counseling, HIV testing, and ARV prophylaxis:

- supplementing clinic staff with lay counselors;

- introducing rapid HIV tests so women can receive same day counseling, HIV testing, and test results;

- improving the quality of HIV and infant feeding counseling by providing job aids and active supervision;

- offering support to PMTCT providers including material support and peer psychosocial support;

- partnering with community groups to offer community education and outreach; and

- expanding the vision of PMTCT to encompass an active role for fathers and male partners.

To strengthen postnatal support and follow up of HIV-infected women and their infants to assist them with infant feeding, getting care for themselves and their families, and to evaluate the program:

PMTCT programs should establish national infant feeding guidelines which include recommendations for HIV-infected women, based on an assessment of local feasibility, acceptability, affordability, safety and sustainability of various feeding options. Also needed are postnatal follow-up protocols including outreach and support groups to help mothers safely apply their infant feeding decision, encourage good maternal nutrition, and address infant feeding after six months. Pilot sites have forged many successful partnerships between the PMTCT program and NGO care and support groups, and scaled-up programs should replicate similar partnerships at all sites. New opportunities for addressing postnatal care for HIV-infected women and enhanced referral links between PMTCT programs and HIV care are currently being devised as part of the development of MTCT-Plus programs. New measurement tools and systems should be developed through field trials, and expanded programs will require monitoring and evaluation staff.

To scale up: PMTCT programs must not only expand to new sites but enlarge the scope of activities within existing sites to reach more women and to provide a comprehensive package of HIV prevention and care. This requires human resources and expertise, coordination and collaboration between partners, a well functioning supply system and resource mobilization. Strong leadership and good coordination of the many institutions and individuals involved is critical to successful scaling up. 


\section{References}

Baek, Carolyn, Marina Xioleth Rodriguez, and Luis Roberto Escoto. 2002. "Report on the Qualitative Rapid Assessment of the UN-Supported PMTCT Pilot Program in Honduras" New York: UNICEF.

Kankasa, C et al. 2002. "Report on the Rapid Assessment of the UN-supported PMTCT pilot program in Zambia." New York: UNICEF

Pham, P, A. Musemakweri, and H. Stewart. 2002. "Report on the Rapid Assessment of the UN-supported PMTCT pilot program in Rwanda." New York: UNICEF.

Population Council and UNICEF. 2002. "PMTCT Evaluation Collaborative Analysis Meeting, Washington DC, September 9-10, 2002.” Meeting Report. New York.

Sarna, A. 2002. "PMTCT Evaluation: Report on Discussions with National AIDS Control Organization and Visits to Two Pilot Program Studies." New York: UNICEF.

UNICEF HIV/AIDS Unit. “PMTCT Programme News.” November 2002. Issue no. 4.

UNICEF and Population Council. 2003. "Program Recommendations for Prevention of Mother-to-Child Transmission of HIV: A Practical Guide for managers." New York.

UNICEF/UNAIDS/WHO/UNFPA. 2000, "African regional meeting on pilot projects for the prevention of Mother-to-child Transmission of HIV." March 27-31. New York.

Synergy. 2003. "Women's Experiences with HIV Serodisclosure in Africa: Implications for VCT and PMTCT"DRAFT Report of a USAID Technical Meeting Sponsored by Office of HIV/AIDS, April 2, 2003: Washington, DC 


\begin{tabular}{|c|c|}
\hline Country & Project Documents \\
\hline Botswana & $\begin{array}{l}\text {-Summary report: Evaluation of Infant feeding practices by mothers at } \\
\text { PMTCT and non PMTCT sites in Botswana } \\
\text {-PMTCT: Evaluation of a Pilot Program and a Follow-up Study of } \\
\text { Infant Feeding Practices during the Scaled-up Program in Botswana } \\
\text {-Botswana PMTCT of HIV Program: MTCT-Plus Proposal } \\
\text {-Draft of UNAIDS Best Practice Document } \\
\text {-PMTCT Infant Feeding: The Botswana Experience PowerPoint } \\
\text { presentation } \\
\text {-Botswana PMTCT: Roll Out Experience PowerPoint presentation }\end{array}$ \\
\hline Burundi & $\begin{array}{l}\text {-Proposal } \\
\text {-UNICEF PMTCT monitoring forms }\end{array}$ \\
\hline Honduras & $\begin{array}{l}\text {-Proposal } \\
\text {-UNICEF PMTCT monitoring forms } \\
\text {-UNAIDS update forms } \\
\text {-KAP study } \\
\text {-Program Protocol } \\
\text {-Key program results PowerPoint presentation }\end{array}$ \\
\hline India & $\begin{array}{l}\text {-Evaluation Report: Feasibility Study of Administering Short Term AZT } \\
\text { Intervention Among HIV Infected Mothers to Prevent MTCT in India } \\
\text {-Prevention of Mother-to-Child Transmission in India, PowerPoint } \\
\text { presentation by Dr. Anne Vincent, Regional Consultation on PMTCT, } \\
\text { Kathmandu, October } 2002 \text {. }\end{array}$ \\
\hline Ivory Coast & -Final narrative report submitted to UNFIP \\
\hline Kenya & $\begin{array}{l}\text {-Bi annual and annual narrative reports } \\
\text {-Final narrative report submitted to UNFIP } \\
\text {-Financial report }\end{array}$ \\
\hline Rwanda & $\begin{array}{l}\text {-Proposal (revised version June 1998) } \\
\text {-Final narrative report to UNFIP } \\
\text {-Financial report }\end{array}$ \\
\hline Tanzania & $\begin{array}{l}\text {-Proposal (third draft) } \\
\text {-Final narrative report submitted to UNFIP } \\
\text {-Financial report } \\
\text {-Integrated PMTCT Training Manual (Volume I and II, 1999) received } \\
\text {-Clinical Guidelines for Health Care Providers in Obstetric Care Services } \\
\text { (1999) } \\
\text {-PMTCT through Breastfeeding (1999) }\end{array}$ \\
\hline Uganda & $\begin{array}{l}\text {-Final narrative report submitted to UNFIP } \\
\text {-Financial report } \\
\text {-Scale up and supply plan }\end{array}$ \\
\hline Zambia & $\begin{array}{l}\text {-Proposal (second draft March 1999) } \\
\text {-Quarterly and annual narrative reports } \\
\text {-Final report submitted to UNFIP } \\
\text {-Financial report }\end{array}$ \\
\hline Zimbabwe & $\begin{array}{l}\text {-Proposal } \\
\text {-Final narrative report submitted to UNFIP } \\
\text {-Financial report }\end{array}$ \\
\hline
\end{tabular}


Appendix B. List of Key Informants

\begin{tabular}{|l|l|}
\hline Country & Interviews \\
\hline Botswana & $\begin{array}{l}\text {-Chewe Luo, UNICEF Focal Point } \\
\text {-Ngongo Ngashi, National Program Manager }\end{array}$ \\
\hline Burundi & $\begin{array}{l}\text {-Daniel Verna, UNICEF Focal Point (PMTCT) } \\
\text {-Terese Nduwimana, UNICEF Focal Point (HIV/AIDS) }\end{array}$ \\
\hline Honduras & $\begin{array}{l}\text { - Xioleth Rodriguez, UNICEF consultant and former National Program } \\
\text { Manager } \\
\text {-Luis Roberto Escoto, UNICEF Focal Point }\end{array}$ \\
\hline India & $\begin{array}{l}\text {-PL Joshi, PMTCT Program Manager (NACO) } \\
\text { - Dr. Barucha, Gynecology Department at BJ Medical College, Pune } \\
\text {-Anne Vincent, UNICEF Focal Point }\end{array}$ \\
\hline Ivory Coast & $\begin{array}{l}\text {-Antoinette Boka-Yayo, UNICEF Focal Point } \\
\text { - Mme Bessa, Ministry for Fight against HIV/AIDS }\end{array}$ \\
\hline Kenya & -Ruth Nduati, NARESA \\
\hline Rwanda & $\begin{array}{l}\text {-Paul Edwards, UNICEF Focal Point } \\
\text { - R. LimLim, UNICEF Focal Point (HIV/AIDS) } \\
\text {-Cecile Ndoli, head of UNICEF PMTCT division } \\
\text {-Ivan Hermans, Director of UNAIDS Rwanda } \\
\text {-Dr. Diouf, Chief of WHO Rwanda } \\
\text {-Laurence Nyiramasarabwe, consultant for WHO } \\
\text {-Solange Shengero, TRAC } \\
\text {-Agnes Binagwaho, PACFA and Office of the First Lady } \\
\text {-Barbara Sow, USAID (TAAC) } \\
\text {-Debra Murray, FHI Impact } \\
\text {-Dr. Martin, FHI Impact } \\
\text {-Sosthene Bucyama, FHI Prime } \\
\text {-Debra Nkusi, World Food Program }\end{array}$ \\
\hline -Meera Shekar, UNICEF Focal Point \\
-Yahya Ipuge, National Program Coordinator, Ministry of Health
\end{tabular}

Additional interviews conducted with Moses Sichone, UNICEF East and Southern Africa Regional Office, Eric Mercier, UNICEF West and Central Africa Regional Office, and Peggy Henderson, UNICEF consultant. 